\title{
REVIEW
}

\section{The design and applications of superomniphobic surfaces}

\begin{abstract}
Arun K Kota ${ }^{1,5}$, Gibum Kwon ${ }^{2,5}$ and Anish Tuteja ${ }^{2,3,4}$
Surfaces that display contact angles $>150^{\circ}$ along with low contact angle hysteresis with essentially all high and low surface tension liquids, including water, oils and alcohols, are known as superomniphobic surfaces. Such surfaces have a range of commercial applications, including self-cleaning, non-fouling, stain-free clothing, drag reduction, corrosion prevention and separation of liquids. Such surfaces have thus generated immense academic and industrial interest in recent years. In this review, we discuss the systematic design of superomniphobic surfaces. In particular, we discuss the significance of surface energy, roughness and the critical role of re-entrant texture in obtaining the so-called Cassie-Baxter state with low surface tension liquids. We also discuss how hierarchical scales of texture can yield high contact angles and decrease the contact angle hysteresis of superomniphobic surfaces by reducing the solid-liquid contact area. On the basis of this understanding, we discuss dimensionless design parameters that allow for the systematic design of superomniphobic surfaces. We also review the current literature on superomniphobic surfaces, paying particular attention to surfaces that demonstrate good mechanical, chemical and radiation durability - traits that are essential for any commercial application of superomniphobic surfaces. Finally, we conclude by identifying the unresolved challenges in the fabrication of durable superomniphobic surfaces and highlight the future needs in the field.
\end{abstract}

NPG Asia Materials (2014) 6, e109; doi:10.1038/am.2014.34; published online 4 July 2014

Keywords: Oil-repellent; Omniphobic; Superhydrophobic; Superoleophobic; Superomniphobic; Water-repellent

\section{INTRODUCTION}

Surfaces that are extremely repellent to (that is, not easily wet by) both high and low surface tension liquids have various military, commercial and specialty applications, including self-cleaning, ${ }^{1}$ nonfouling, ${ }^{2}$ stain-free clothing and spill-resistant protective wear, ${ }^{3}$ drag reduction, ${ }^{4}$ corrosion prevention, ${ }^{5}$ locomotion of microrobots on aqueous and chemical environments ${ }^{6,7}$ and separation of liquids. ${ }^{8}$ The wettability of a surface against any liquid is typically characterized by two parameters-contact angle and contact angle hysteresis. ${ }^{9}$

On a non-textured (or smooth) surface, the equilibrium contact angle $\theta$ for any contacting liquid is given by Young's relation ${ }^{10}$ as:

$$
\cos \theta=\frac{\gamma_{S V}-\gamma_{S L}}{\gamma_{L V}}
$$

Here, $\gamma$ refers to the interfacial tension and $S, L$ and $V$ refer to the solid, liquid and vapor phases, respectively. The solid-vapor interfacial tension $\left(\gamma_{S V}\right)$ and the liquid-vapor interfacial tension $\left(\gamma_{L V}\right)$ are also commonly referred to as the solid surface energy and the liquid surface tension, respectively. Based on the contact angle $\theta$ of a water droplet, a surface can be classified as superhydrophilic when $\theta \approx 0^{\circ}$ (see Figure 1a), hydrophilic when $\theta<90^{\circ}$ (see Figure 1b) and hydrophobic when $\theta>90^{\circ}$ (see Figure 1c). Note that the maximum contact angle of a water droplet reported on a non-textured surface is about $130^{\circ} .11,12$ Under certain conditions, textured surfaces can display much higher contact angles with a contacting liquid (as described in 'Wetting on rough surfaces - the Cassie-Baxter state and the Wenzel state' section). Similar to water, based on the contact angle of a low surface tension liquid (such as an oil or an alcohol or another organic solvent) droplet, surfaces can be classified as superoleophilic, oleophilic and oleophobic.

The second important parameter for characterizing surface wettability, contact angle hysteresis, is defined as the difference between the advancing (which is the maximum) and the receding (which is the minimum) contact angles on a solid surface. Typically, contact angle hysteresis arises due to surface roughness and heterogeneity. ${ }^{13,14}$ Physically, it is a measure of the energy dissipated during the motion of a liquid droplet along a solid surface. Contact angle hysteresis is a strong function of the total interfacial area between the solid surface and the liquid droplet. The lower the solid-liquid interfacial area, the lower is the contact angle hysteresis.

A surface is considered to be super-repellent when it displays very high contact angles (typically $>150^{\circ}$ as shown in Figure 1d) and very

${ }^{1}$ Department of Mechanical Engineering, Colorado State University, Fort Collins, CO, USA; ${ }^{2}$ Department of Materials Science and Engineering, University of Michigan, Ann Arbor, MI, USA; ${ }^{3}$ Macromolecular Science and Engineering, University of Michigan, Ann Arbor, MI, USA and ${ }^{4}$ Department of Chemical Engineering, University of Michigan, Ann Arbor, MI, USA 5These authors contributed equally to this work.

Correspondence: Professor A Tuteja, Department of Materials Science and Engineering, University of Michigan, 2800 plymouth Road, Building 10, Room A185, Ann Arbor, MI 48109, USA.

E-mail: atuteja@umich.edu

Received 28 October 2013; revised 16 January 2014; accepted 27 February 2014 

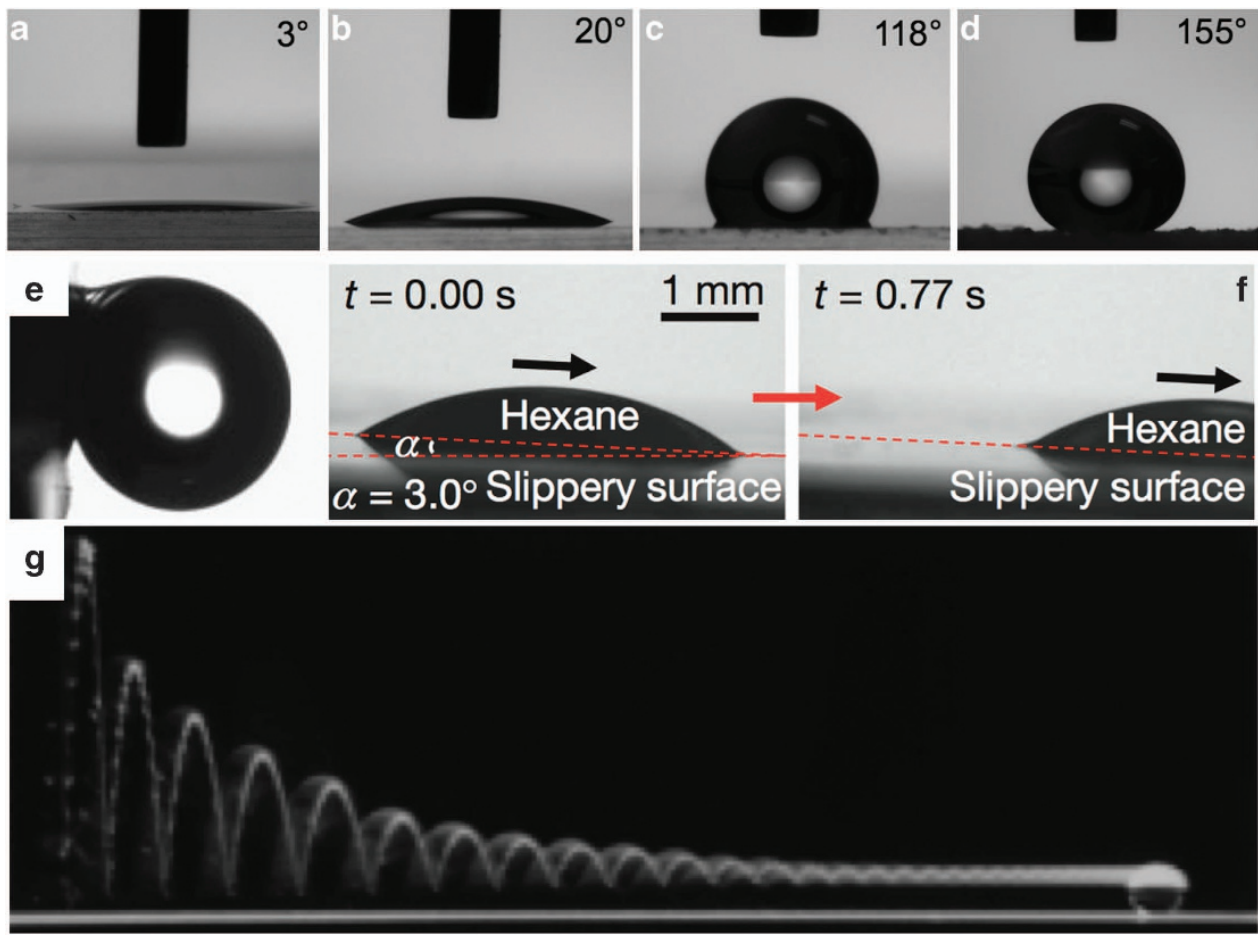

Figure 1 Surface classification based on contact angles. (a) Superhydrophilic, (b) hydrophilic and (c) hydrophobic surfaces display $\theta \approx 0^{\circ}, \theta<90^{\circ}$ and $\theta>90^{\circ}$, respectively, with water. (d) Superhydrophobic surfaces display $\theta^{*}>150^{\circ}$ and very low contact angle hysteresis $\left(<5^{\circ}\right)$ with water. (e) 'Sticky nonwetting surfaces' display $\theta^{*}>150^{\circ}$ and extremely high hysteresis. The surface is tilted by $90^{\circ}$. Reprinted with permission from Jin et al.20 $\odot 2005$ Wiley. (f) Slippery liquid infused surfaces that display low contact angles and low hysteresis. Reprinted with permission from Wong et al. ${ }^{26} \odot 2011$ Nature publishing group. (g) Bouncing of a water droplet on a superhydrophobic surface. Such bouncing requires both high contact angles and low hysteresis Reprinted with permission from Richard and Quere. ${ }^{30}$ ๑) 2000 IOP Science.

low contact angle hysteresis (typically $<5^{\circ}$ ) for a contacting liquid. ${ }^{9,15,16}$ Typically, when a surface displays very high contact angles and high contact angle hysteresis, the liquid droplets tend to stick to the surface (see Figure 1e). In contrast to such 'sticky nonwetting surfaces,'17-23 super-repellent surfaces display low contact angle hysteresis and facilitate easy roll off of the contacting liquid droplets. There have also been reports of surfaces that display low contact angles and low contact angle hysteresis (see Figure 1f). Although liquid droplets can easily slide on such 'slippery surfaces, $^{24-29}$ bouncing of liquid droplets ${ }^{30}$ (see Figure $1 \mathrm{~g}$ ) is limited only to the conventional super-repellent surfaces.

When a surface displays contact angles $>150^{\circ}$ and contact angle hysteresis $<5^{\circ}$ for water, it is considered a superhydrophobic surface. Superhydrophobic surfaces are pervasive in nature (see Figures $2 \mathrm{a}-\mathrm{d}$ ) with various plant leaves, ${ }^{31-33}$ legs of the water strider, ${ }^{34-36}$ gecko's feet, ${ }^{2,37}$ troughs on the elytra of desert beetles, ${ }^{38}$ and insect wings, ${ }^{39}$ displaying extreme water-repellency. Inspired by natural superhydrophobic surfaces, several researchers have also engineered artificial (or synthetic) superhydrophobic surfaces. ${ }^{11,40-42}$

When a surface displays contact angles $>150^{\circ}$ and contact angle hysteresis $<5^{\circ}$ for low surface tension liquids such as oils, alcohols or other organic solvents, it is considered as a superoleophobic surface. In spite of numerous natural superhydrophobic surfaces and rare natural oleophobic surfaces (see Figure 2e) ${ }^{43}$ there are no known naturally occurring superoleophobic surfaces. This is because oils possess significantly lower surface tension values than water and consequently spread on most surfaces. However, based on previous work $^{44-54}$ that recognized the importance of re-entrant texture (that is, convex topography, see Figure 2e; also explained in 'Critical role of re-entrant texture' section) in designing oil-repellent surfaces, several researchers have now engineered artificial (or synthetic) superoleophobic surfaces. ${ }^{9,55-57}$

Typically, most surfaces that repel lower surface tension liquids, such as oil, can also repel higher surface tension liquids, such as water. Consequently, most superoleophobic surfaces are also superhydrophobic. However, recently, surfaces that are superoleophobic and yet superhydrophilic have been reported. ${ }^{58,59}$ In order to distinguish from such counter-intuitive surfaces, we define surfaces that display both superhydrophobicity and superoleophobicity as superomniphobic surfaces.

In this review, we discuss the systematic design of superomniphobic surfaces. We discuss the significance of surface energy, roughness and the critical role of re-entrant texture in obtaining the so-called CassieBaxter state $^{60}$ with low surface tension liquids. We also discuss how hierarchical scales of texture (that is, texture on two or more length scales, see Figure $2 \mathrm{~b}$; also explained in 'Significance of hierarchical scales of texture' section) can yield high contact angles and decrease the contact angle hysteresis of superomniphobic surfaces by reducing the solid-liquid contact area. On the basis of this understanding, we discuss dimensionless design parameters that allow for the systematic design of superomniphobic surfaces. We also present a review of the current literature on superomniphobic surfaces with a single scale of texture, as well as hierarchical scales of texture. Practical applications of superomniphobic surfaces require good mechanical, chemical and radiation durability. With this in view, we present a few examples of the current state-of-the-art durable superomniphobic surfaces, while 

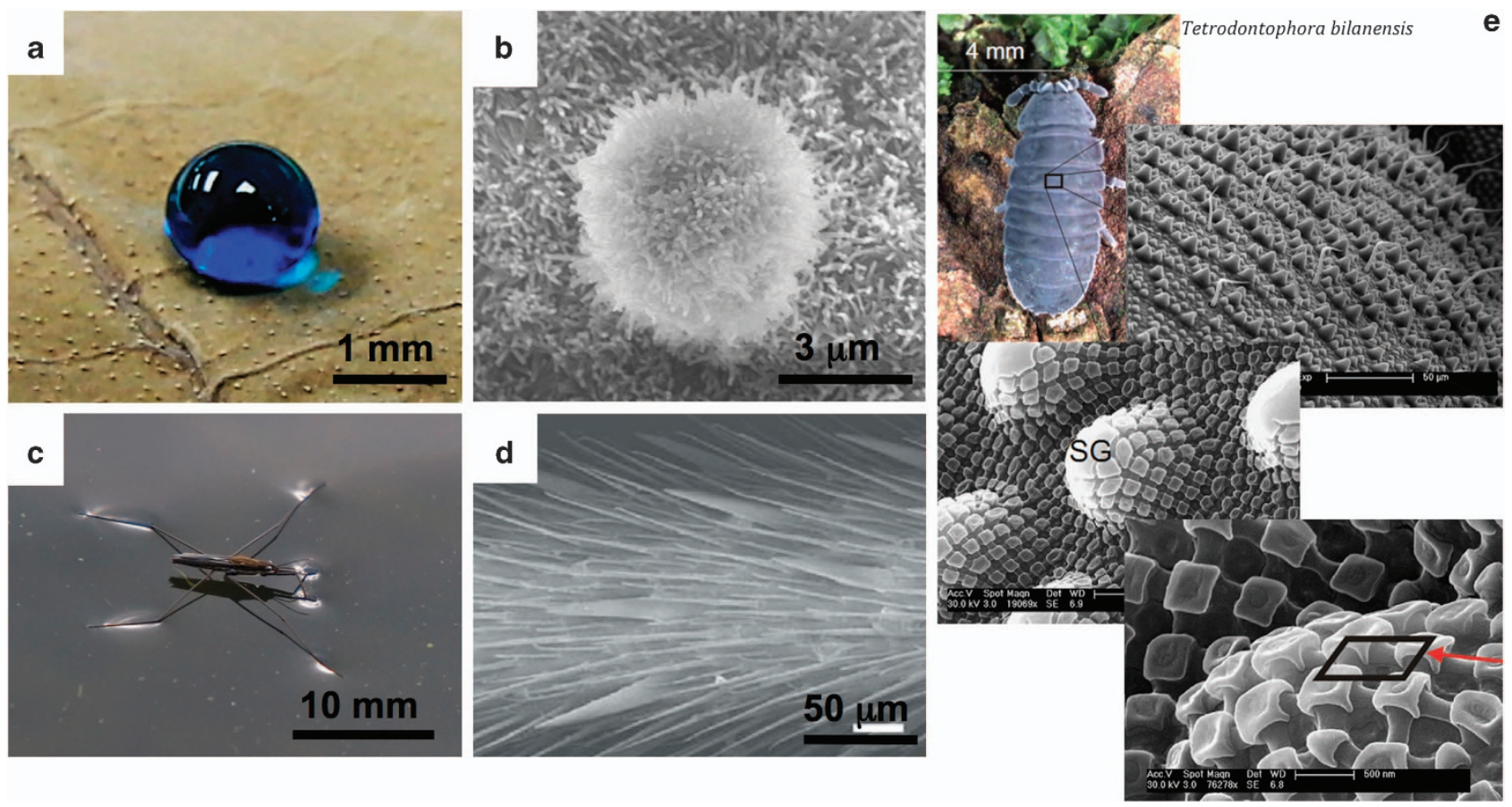

Figure 2 Naturally occurring super-repellent surfaces. (a) A droplet of water (blue) displaying very high contact angle on a lotus leaf. (b) An s.e.m. image of a lotus leaf showing its rough, hierarchical texture. (c) A water strider walking on the water surface. (d) An s.e.m. image of a water strider's leg, which consists of numerous oriented hairs. Reprinted with permission from Gao and Jiang. ${ }^{36} \odot 2004$ Nature Publishing Group. (e) A picture and s.e.m. images of hierarchical structured springtails skin where secondary granules (SG) are superimposed on primary granules. Note that the SG possess re-entrant texture, which allows springtail skin to be oleophobic. Reprinted with permission from Helbig et al. ${ }^{43}$ @ 2011 PLOS.

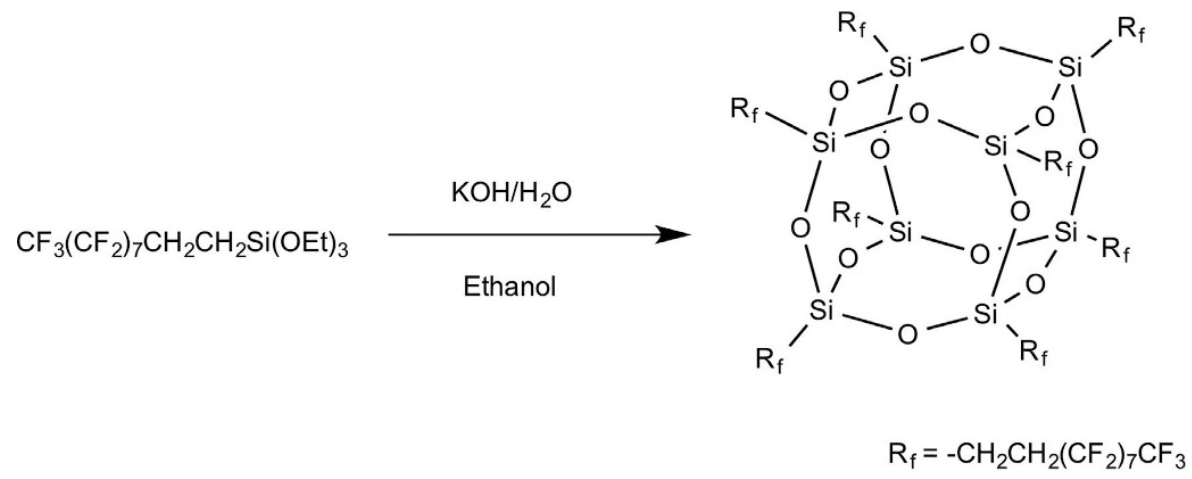

Figure 3 Synthesis of fluorodecyl POSS. A scheme depicting the synthesis of fluorodecyl POSS. Adapted with permission from Mabry et al. ${ }^{62} \odot 2008$ Wiley.

emphasizing the unresolved challenges. We also highlight a few applications of superomniphobic surfaces. Finally, we conclude by identifying the potential for further improvements in the field.

\section{NEED FOR LOW SURFACE ENERGY}

It is evident from the Young's relation (Equation (1)) that the solid surface energy $\gamma_{S V}$ is inversely proportional to the contact angle $\theta$. This implies that surfaces with very high surface energy tend to display lower contact angles, while surfaces with very low surface energy tend to display higher contact angles. Therefore, surfaces with low surface energy are preferred for the design of super-repellant surfaces. Zisman and Co-workers ${ }^{61}$ reported that among various surface functional groups, the surface energy decreases in the order $-\mathrm{CH}_{2}>-\mathrm{CH}_{3}>-\mathrm{CF}_{2}>-\mathrm{CF}_{2} \mathrm{H}>-\mathrm{CF}_{3}$. Consequently, fluorinated and perfluorinated materials, including perfluorinated phosphates, perfluorinated silanes, fluorinated monomers, polymers and copolymers, and other fluorinated precursors have become the logical choice of materials used in designing superomniphobic surfaces. $^{56}$ Of all the perfluorinated materials, FluoroPOSS (Fluorinated Polyhedral Oligomeric SilSesquioxanes) molecules deserve a special mention, because they are among the lowest surface energy materials ever produced. ${ }^{45,46}$ FluoroPOSS molecules are polyhedral oligomeric silsesquioxane cages $^{62}$ surrounded by fluoroalkyl functional groups with no surrounding hydrocarbon periphery, other than the methylene groups immediately adjacent to the silicon atoms. FluoroPOSS compounds can be synthesized in a single-step, base-catalyzed condensation reaction of fluoroalkyltrialkoxysilanes. ${ }^{62}$ For example, synthesis of octameric 
$\left(1 \mathrm{H}, 1 \mathrm{H}, 2 \mathrm{H}, 2 \mathrm{H}\right.$-heptadecafluorodecyl) ${ }_{8} \mathrm{Si}_{8} \mathrm{O}_{12}$ POSS (Fluorodecyl POSS) was achieved via condensation of $(1 \mathrm{H}, 1 \mathrm{H}, 2 \mathrm{H}, 2 \mathrm{H}-$ heptadecafluorodecyl)triethoxysilane in an alcoholic solvent, as shown in Figure 3. Fluorodecyl POSS has a surface energy of $\gamma_{S V}$ $\sim 10 \mathrm{mN} \mathrm{m}^{-1} .^{62}$ Further, it is very stable and chemically resistant to a wide variety of solvents, making it extremely useful for the fabrication of superomniphobic surfaces.

\section{WETTING ON ROUGH SURFACES-THE CASSIE-BAXTER STATE AND THE WENZEL STATE}

The wettability of a liquid on a rough surface can be very different from that on a smooth surface. When a liquid droplet contacts a textured substrate, it can adopt one of the following two configurations to minimize its overall free energy ${ }^{13,52,53,63,64}$ - the Wenzel ${ }^{65}$ state or the Cassie and Baxter ${ }^{60}$ state. In the Wenzel state, the contacting liquid droplet completely permeates the surface protrusions, as shown in Figure $4 \mathrm{a}$, forming the so-called 'fullywetted' interface. In this state, the apparent contact angles can be determined using the Wenzel relation, ${ }^{65}$ given as:

$\cos \theta^{*}=r \cos \theta$

Here, $r$ is the surface roughness, which is defined as the ratio of the actual surface area to the projected surface area. As $r$ is always greater than unity, roughness amplifies both the wetting and non-wetting behavior of surfaces in the Wenzel state. In other words, $\theta^{*}<<90^{\circ}$ if $\theta<90^{\circ}$ and $\theta^{*}>>90^{\circ}$ if $\theta>90^{\circ}$. Typically, liquids with low surface tension, such as different oils and alcohols, display Young's contact angle $\theta<90^{\circ}$. Consequently, low surface tension liquids tend to display very low contact angles in the Wenzel state.

On the other hand, in the Cassie-Baxter state, the liquid does not completely wet the surface texture, as shown in Figure $4 \mathrm{~b}$. Instead, pockets of air remain trapped underneath the liquid droplet. The liquid penetrates into the surface texture until the local texture angle $(\psi)$ for the three-phase contact line becomes equal to the equilibrium contact angle $\theta$ (given by Young's relation). ${ }^{52,53}$ The apparent contact angles in this state can be determined using the Cassie-Baxter relation, ${ }^{60,66}$ given as:

$$
\cos \theta^{*}=f_{S L} \cos \theta+f_{L V} \cos \pi=f_{S L} \cos \theta-f_{L V}
$$
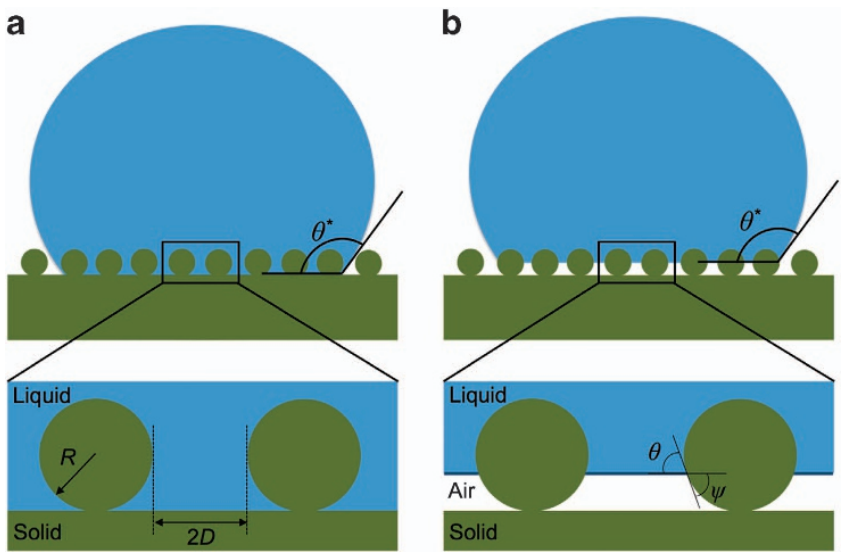

Figure 4 Liquid droplets on textured solid surfaces. (a, b) Schematic illustrations of a liquid droplet in the Wenzel state and the Cassie-Baxter state, respectively. In these schematics, $R$ is the radius of the feature and $2 D$ is the inter-feature spacing. Note that surfaces possessing re-entrant texture $\left(\psi<90^{\circ}\right)$ can support a robust composite (solid-liquid-air) interface even for low surface tension liquids that display $\theta<90^{\circ}$.

Here, $f_{S L}$ is the area fraction of the solid-liquid interface, which can be computed from the relation $f_{S L}=r_{\phi} \phi_{S} ; f_{L V}$ is the area fraction of the liquid-air interface underneath the liquid droplet on a surface with uniform roughness. Note that $r_{\phi}$ is the roughness ratio of the wetted area and $\phi_{s}$ is the area fraction of the projected liquid-air interface occluded by the surface texture. ${ }^{52}$ On surfaces with non-uniform roughness, $f_{S L}$ and $f_{L V}$ represent the local area fractions of the solid-liquid interface and the liquid-air interface, respectively, in the vicinity of the three-phase (solid-liquid-air) contact line. ${ }^{67}$ It is evident from Equation (3) that the CassieBaxter state can lead to apparent contact angle $\theta^{*}>>90^{\circ}$ not only for $\theta>90^{\circ}$ but also for $\theta<90^{\circ}$, provided the solid-liquid area fraction $f_{S L}$ is sufficiently low and the liquid-air area fraction $f_{L V}$ is sufficiently high. In other words, in contrast to the Wenzel state, the formation of the Cassie-Baxter state can lead to very high contact angles even for low surface tension liquids. Further, the lower solid-liquid area fraction $f_{S L}$ leads to a lower contact angle hysteresis $\left(\Delta \theta^{*}\right)$ for the Cassie-Baxter state when compared with the Wenzel state. ${ }^{41,42,68}$ Consequently, the Cassie-Baxter state is preferred in designing superomniphobic surfaces with high apparent contact angles $\left(\theta^{*}\right)$ and low contact angle hysteresis.

\section{CRITICAL ROLE OF RE-ENTRANT TEXTURE}

Although the formation of the Cassie-Baxter state is desirable in designing superomniphobic surfaces, not all types of textures can lead to a Cassie-Baxter state with low surface tension liquids, which display a Young's contact angle $\theta<<90^{\circ}$. To illustrate this qualitatively, consider the two types of textures shown in Figures $5 \mathrm{a}$ and $\mathrm{b}$, both having the same solid surface energy. The texture shown in Figure $5 \mathrm{a}$ is concave (texture angle $\psi>90^{\circ}$ ) and the texture shown in Figure $5 \mathrm{~b}$ is convex $\left(\psi<90^{\circ}\right)$ facing upwards. In both the cases, any liquid contacting the texture in the Cassie-Baxter state locally displays a contact angle equal to the Young's contact angle $\theta$. A stable CassieBaxter state results only when $\theta \geqslant \psi \cdot{ }^{45,49,52,53}$ This is because if $\theta<\psi$, the net traction on the liquid-vapor interface is downward due to the capillary force, which promotes imbibition of the liquid into the solid texture, leading to a fully wetted Wenzel state. Consequently, low surface tension liquids, which display a Young's contact angle $\theta<90^{\circ}$, cannot be in a stable Cassie-Baxter state on textures with $\psi>90^{\circ}$ (Figure 5a). However, they can be in a robust Cassie-Baxter state on textures with $\psi<90^{\circ}$ (Figure $5 \mathrm{~b}$ ). Such convex topographies, with $\psi<90^{\circ}$, are called re-entrant textures. Re-entrant texture (such as the texture of the springtail skin shown in Figure 2e) is necessary in designing superomniphobic surfaces. However, it must be noted that re-entrant texture that enables the condition $\psi \leqslant \theta$ for low surface tension liquids, is a necessary, but not a sufficient, condition ${ }^{49,52,53}$ for the formation of a robust Cassie-Baxter state, as discussed in 'Design parameters and design strategies for superomniphobic surfaces' section.

a

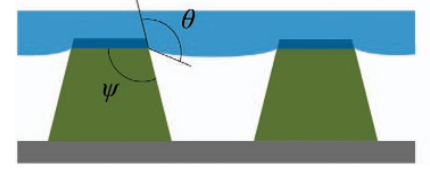

Figure 5 The critical role of re-entrant texture. (a) A schematic of a concave texture $\left(\psi>90^{\circ}\right)$ showing a liquid droplet with $\theta>90^{\circ}$ in the Cassie-Baxter state. (b) A schematic of a convex texture (re-entrant texture, $\psi<90^{\circ}$ ) showing a lower surface tension liquid with $\theta<90^{\circ}$ in the Cassie-Baxter state. b

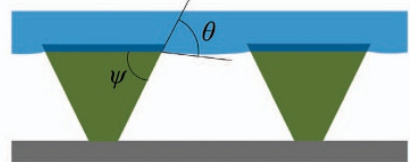




\section{SIGNIFICANCE OF HIERARCHICAL SCALES OF TEXTURE}

Most naturally occurring surfaces that are repellent to liquids possess a hierarchical structure, that is, more than one length scale of texture (see Figure 2). Typically, hierarchically structured surfaces consist of a finer length scale texture on an underlying coarser length scale texture (see Figures $6 \mathrm{a}-\mathrm{c}$ ). When a hierarchically structured surface supports a contacting liquid droplet in the Cassie-Baxter state at all length scales, the liquid droplet typically displays higher apparent contact angles compared with surfaces with a single scale of texture. This is because air is trapped at multiple length scales for a hierarchically structured surface, while air is trapped only at one length scale for surfaces with a single scale of texture. The apparent contact angles on a hierarchically structured surface can be determined by recursively writing the Cassie-Baxter relation as: ${ }^{44,54}$

$$
\cos \theta_{n}^{*}=\left(1-f_{L V, n}\right) \cos \theta_{n-1}^{*}-f_{L V, n}
$$

Here, $n=1,2,3,4$ and so on, and is the number of length scales of texture; $f_{L V, n}$ is the area fraction of the liquid-air interface for the $n$th scale of texture; $\theta_{n}^{*}$ and $\theta_{n-1}^{*}$ are the apparent contact angles on hierarchically structured surfaces with $n$ scales of texture and $n-1$ scales of texture, respectively. It is evident from Equation (4) that $\theta_{n}^{*}$ increases as the number of scales of texture $n$ increases.

Hierarchically structured surfaces that can support a contacting liquid droplet in the Cassie-Baxter state also display lower contact angle hysteresis compared with surfaces with a single scale of texture. ${ }^{15,16,69-71}$ As mentioned in the first section, contact angle hysteresis is related to energy barriers that a liquid droplet must overcome during its movement along a solid surface and thus characterizes the resistance to the droplet movement. ${ }^{13,14}$ Lower solid-liquid contact area leads to lesser contact line pinning (that is, lower resistance to droplet movement) and consequently lower contact angle hysteresis. Typically, hierarchically structured surfaces (see Figure 6c) have significantly lower solid-liquid contact area compared with surfaces that possess a single scale of texture (see Figures $6 \mathrm{a}$ and $\mathrm{b}$ ). This results in significantly lower contact angle hysteresis.

In addition, theoretical analysis ${ }^{53}$ has shown that hierarchically structured surfaces can enhance the stability of the Cassie-Baxter state by providing more locations where the composite interface can be stable. Recent theoretical work ${ }^{72,73}$ has also shown that, with increasing number of scales of texture, the overall free energy increasingly favors the Cassie-Baxter state over the Wenzel state. Consequently, hierarchically structured surfaces possessing re-entrant texture, which can support low surface tension liquids in the CassieBaxter state, are ideal for designing superomniphobic surfaces.

\section{DESIGN PARAMETERS AND DESIGN STRATEGIES FOR SUPEROMNIPHOBIC SURFACES}

It is evident from the previous sections that the formation of a Cassie-Baxter state with low surface tension liquids is necessary to obtain superomniphobicity. The Cassie-Baxter state can be parameterized in terms of two important physical characteristics-(a) the magnitude of the observed apparent contact angle $\theta^{*}$ and (b) the magnitude of the breakthrough pressure $P_{\text {breakthrough }}$ that is, the minimum pressure that can force a transition from the Cassie-Baxter state to the fully wetted Wenzel state. Recall from section 'Critical role of re-entrant texture' that re-entrant texture is a necessary but not a sufficient condition for the formation of the Cassie-Baxter state with low surface tension liquids. ${ }^{49,52,53}$ In addition to possessing re-entrant texture, a superomniphobic surface should possess a sufficiently high breakthrough pressure $P_{\text {breakthrough }}$ to withstand the applied pressure $P_{\text {applied }}$ (for example, Laplace pressure, hydrostatic pressure and so on) from the contacting low surface tension liquid. In other words, a superomniphobic surface must be designed in a manner that $P_{\text {breakthrough }}>P_{\text {applied }}$ to prevent the transition from the CassieBaxter state to the Wenzel state.

Systematic design of superomniphobic surfaces requires dimensionless parameters that can relate the surface texture and the surface chemistry to the apparent contact angle $\theta^{*}$ and the breakthrough pressure $P_{\text {breakthrough }}$. Previous work ${ }^{44-46}$ has addressed this issue by developing two dimensionless parameters-the spacing ratio $D^{*}$ and the robustness factor $A^{*}$. Physically, the spacing ratio $D^{*}$ is a dimensionless measure of the surface porosity. Higher values of $D^{*}$ correspond to a higher fraction of air trapped at the composite interface and consequently higher apparent contact angles $\theta^{*}$. For substrates possessing a predominantly cylindrical texture, $D_{\text {clinder }}^{*}=(R+D) / R$, while for substrates possessing a predominantly spherical texture, $D_{\text {sphere }}^{*}=[(R+D) / R]^{2}$. Here, $R$ is the radius of the cylinder (or sphere) and $2 D$ is the inter-cylinder (or inter-sphere) spacing (see Figure 4). Based on this definition of the spacing ratio, the Cassie-Baxter relation (Equation (3)) may be rewritten for surfaces possessing a cylindrical (Equation (5)) or a spherical (Equation (6)) texture as: ${ }^{44,74}$

$$
\begin{aligned}
& \cos \theta_{\text {cylinder }}^{*}=-1+\frac{1}{D_{\text {cylinder }}^{*}}[\sin \theta+(\pi-\theta) \cos \theta] \\
& \cos \theta_{\text {sphere }}^{*}=-1+\frac{1}{D_{\text {sphere }}^{*}}\left[\frac{\pi}{2 \sqrt{3}}(1+\cos \theta)\right]^{2}
\end{aligned}
$$

Recall from 'Significance of hierarchical scales of texture' section that the Cassie-Baxter relation can be written recursively for hierarchically structured surfaces. Consequently, the effective spacing ratio $D_{\text {hierarchical }}^{*}$ for hierarchically structured surfaces is significantly higher than that for surfaces with a single scale of texture. It is evident from Equations (5) and (6) that $\theta^{*}$ increases with increasing values of $D^{*}$. However, for large values of the inter-feature spacing $D$, which typically yield very high values for the spacing ratio, that is, $D^{*}>>1$, it may be expected that the surface can no longer support the contacting liquid in the Cassie-Baxter state and allows the liquid to breakthrough.
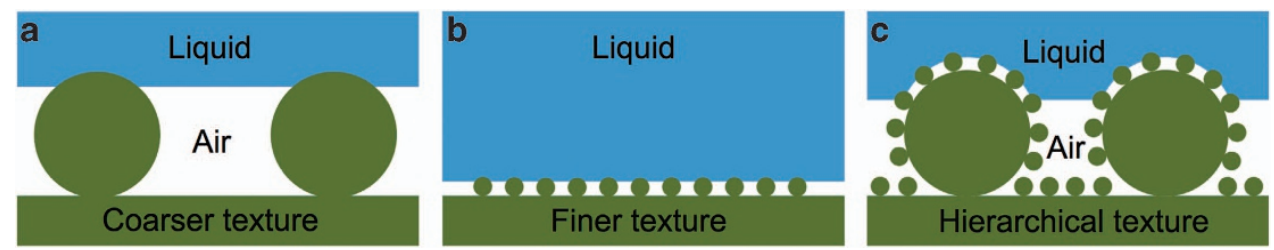

Figure 6 The need for hierarchical scales of texture. (a-c) Schematics of a liquid droplet in the Cassie-Baxter state on a coarser textured surface, a finer textured surface and a hierarchically textured surface, respectively. 
The robustness factor $A^{*}$ is a measure of the breakthrough pressure $P_{\text {breakthrough }}$ for a known surface texture and surface chemistry. $A^{*}$ is defined as the ratio of the breakthrough pressure $\left(P_{\text {breakthrough }}\right)$ to a reference pressure $P_{\text {ref }}=2 \gamma_{L V} / l_{\text {cap }}$. Here, $l_{\text {cap }}=\sqrt{\gamma_{L V} / \rho g}$ is the capillary length for the liquid, $\rho$ is the liquid density and $g$ is the acceleration due to gravity. $P_{r e f}$ is close to the minimum possible pressure differential across a millimeter-sized liquid droplet or a puddle. ${ }^{45}$ As a consequence, substrates on which the robustness factor $A^{*} \leqslant 1$ for a given contacting liquid cannot support a composite interface. On the other hand, values of $A^{*}$ significantly greater than unity imply the formation of a robust composite interface that can withstand high breakthrough pressures. The robustness factors for a known surface texture and surface chemistry can be developed through a force balance at the composite interface. ${ }^{44-46}$ The robustness factors for surfaces possessing a predominantly cylindrical (Equation (7)) or a spherical (Equation (8)) texture are given as: ${ }^{44,74}$

$$
\begin{aligned}
A_{\text {cylinder }}^{*} & =\frac{P_{\text {breakthrough }}}{P_{\text {ref }}} \\
& =\frac{l_{\text {cap }}}{R\left(D_{\text {cylinder }}^{*}-1\right)} \frac{(1-\cos \theta)}{\left(D_{\text {cylinder }}^{*}-1+2 \sin \theta\right)} \\
A_{\text {sphere }}^{*}= & \frac{P_{\text {breakthrough }}}{P_{\text {ref }}} \\
= & \frac{2 \pi l_{\text {cap }}}{R\left(2 \sqrt{3} D_{\text {sphere }}^{*}-\pi\right)} \frac{(1-\cos \theta)}{\left(\sqrt{D_{\text {sphere }}^{*}}-1+2 \sin \theta\right)}
\end{aligned}
$$

For a hierarchically structured surface composed of multiple scales of texture, the composite interface is typically the least stable on the texture with the largest inter-feature spacing. ${ }^{44}$ Consequently, the magnitude of the robustness factor $A_{\text {hierarchical }}^{*}$ for a hierarchically structured surface is equal to the robustness factor for the texture with the largest inter-feature spacing.

Optimal superomniphobic surfaces need to simultaneously display high contact angles and high breakthrough pressures with the contacting liquid. Thus, they must be designed with both $D^{*}>>1$ and $A^{*}>>1$. However, as evident from Equations (7) and (8), $A^{*}$ decreases with increasing $D^{*}$. This is also evident from the design chart (see Figure 7) that shows a plot of the robustness factor $A^{*}$ as a function of $D^{*}$. However, there are strategies to-(a) increase $A^{*}$ (and consequently $P_{\text {breakthrough }}$ ) without compromising $D^{*}$, and (b) to increase $D^{*}$ (and consequently $\theta^{*}$ ) without compromising $A^{*}$. First, the robustness factor $A^{*}$ can be increased while maintaining the same spacing ratio $D^{*}$ by decreasing the length scale of the texture. For example, consider a spherical microstructure with a known feature size $R_{\text {micro }}$ inter-feature spacing $D_{\text {micro }}$, spacing ratio $D_{\text {micro }}^{*}$ and robustness factor $A_{\text {micro }}^{*}$. Now, consider decreasing the length scale of the texture to a spherical nanostructure with feature size $R_{\text {nano }}$ and inter-feature spacing $D_{\text {nano }}$ such that $D_{\text {micro }}^{*}=\left[\left(R_{\text {micro }}+D_{\text {micro }}\right)\right.$ $\left./ R_{\text {micro }}\right]^{2}=D_{\text {nano }}^{*}=\left[\left(R_{\text {nano }}+D_{\text {nano }}\right) / R_{\text {nano }}\right]^{2}$. It is evident from Equations (7) and (8) that $A_{\text {nano }}^{*} \gg A_{\text {micro }}^{*}$. In this manner, by decreasing the length scale of the texture, the robustness factor $A^{*}$ can be increased while maintaining the same spacing ratio $D^{*}$. On the other hand, the spacing ratio $D^{*}$ can be increased while maintaining the same robustness factor $A^{*}$ by increasing the number of hierarchical scales of texture. For example, consider a spherical microstructure with a known spacing ratio $D_{\text {micro }}^{*}$ and robustness factor $A_{\text {micro. }}^{*}$. Now, consider making the hierarchical texture formed by superimposing spherical nanostructures on top of the spherical microstructure (as shown in Figure 6c). Recall that the composite interface is typically the least stable on the texture with the largest inter-feature spacing. This implies that $A_{\text {hierarchical }}^{*} \approx A_{\text {micro. }}^{*}$. Recalling that air is trapped at multiple length scales of a hierarchical structure, it is evident that $D_{\text {hierarchical }}^{*}>D_{\text {micro }}^{*}$. In this manner, by increasing the number of hierarchical scales of texture, the spacing ratio $D^{*}$ can be increased while maintaining the same robustness factor $A^{*}$. The wide variety of fabrication techniques available to us today (see 'Recent work on superomniphobic surfaces' section) make it possible to precisely fabricate microstructures, nanostructures and hierarchical structures and thereby tune the spacing ratio $D^{*}$ and the robustness factor $A^{*}$. This in turn allows the systematic design of superomniphobic surfaces for optimal performance in any desired application.

\section{RECENT WORK ON SUPEROMNIPHOBIC SURFACES}

Currently, there are hundreds of published reports on superhydrophobic surfaces. In comparison, there are significantly fewer reports on superoleophobic or superomniphobic surfaces. However, the number of reports on superomniphobic surfaces is rapidly increasing every year with more and more researchers recognizing the importance of hierarchically structured surfaces with re-entrant texture in designing superomniphobic surfaces. There are two important criteria related to characterization of the superomniphobic surfaces that are sometimes neglected in the literature. First, superomniphobic surfaces display apparent contact angles $\theta^{*}>150^{\circ}$ with both high and low surface tension liquids, as well as low contact angle hysteresis $\Delta \theta^{*} ., 15,16$ Reporting just the static contact angle $\theta^{*}$ or the apparent advancing contact angle $\theta_{a d v}^{*}>150^{\circ}$ for liquids does not adequately describe superomniphobicity. The apparent receding contact angle $\theta_{\text {rec }}^{*}$, contact angle hysteresis or roll-off angle (that is, the minimum angle $\alpha$ by which the substrate must be tilted for the droplet to roll off from the surface) must be measured and reported, because they are useful in estimating the ease of droplet roll-off and bouncing.

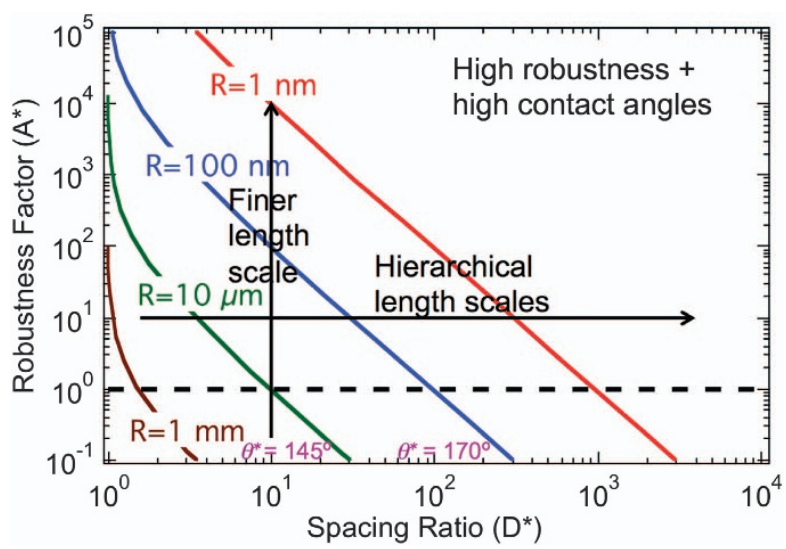

Figure $7 \mathrm{~A}$ design chart illustrating the variation of the robustness factor with the spacing ratio. A plot of the robustness factor $A^{*}$ as a function of the spacing ratio $D^{*}$ for octane $\left(\gamma / v=21.7 \mathrm{mN} \mathrm{m}^{-1}\right)$ on cylindrical fibers; assumed value of $\theta=60^{\circ}$. Reprinted with permission from Choi et al. ${ }^{44}$ (C) 2009 Wiley. Typically, as the spacing ratio increases, the robustness factor decreases. Designing surfaces with finer length scales allows for the increase in robustness factor while maintaining a fixed contact angle or spacing ratio (traversing along the $y$ axis). On the other hand, designing surfaces with a hierarchical texture allows for the increase in contact angle, while maintaining a fixed robustness factor or breakthrough pressure (traversing along the $x$ axis). 
Obtaining a low contact angle hysteresis (typically $\Delta \theta^{*}<5^{\circ}$ ) and low roll-off angles (typically $\alpha<5^{\circ}$ ) for low surface tension liquids is perhaps as important as the maximum achievable contact angle in qualifying the superomniphobicity of a surface. Second, there is some ambiguity regarding which liquid or liquids must be used in characterizing superomniphobicity. In literature, it is sometimes difficult to compare across different superomniphobic surfaces, because many liquids ranging in surface tension from heptane $\left(\gamma_{L V}=20.1 \mathrm{mN} \mathrm{m}^{-1}\right)$ to diiodomethane $\left(\gamma_{L V}=50.8 \mathrm{mN} \mathrm{m}^{-1}\right)$ have been used as representative oils for contact angle measurements. In some reports, the surface tension of the oil is not mentioned at all. In some other reports, claims of superomniphobicity are based on liquids such as diiodomethane and glycerol, which possess a relatively high surface tension. In order to allow easier comparison across literature, it is important to measure and report the advancing contact angles, as well as receding contact angles or contact angle hysteresis or roll-off angles, for a variety of polar and non-polar liquids, especially for those possessing a sufficiently low surface tension $\left(\gamma_{L V}<30 \mathrm{mN} \mathrm{m}^{-1}\right)$.

One of the first reports on surfaces displaying very high contact angles with low surface tension liquids dates back to the work of Tsujii et al..$^{75}$ in 1997 . They developed an anodically oxidized aluminum surface with a fractal structure, which was modified with perfluorodecyl phosphate or perfluorododecyl phosphate. The resulting surface displayed $\theta^{*}=150^{\circ}$ with rapeseed oil $\left(\gamma_{L V}=35.7 \mathrm{mN} \mathrm{m}^{-1}\right.$, see Figure $\left.8 \mathrm{a}\right)$. Further, oil droplets rolled around even if the substrate was only slightly tilted, ${ }^{76}$ indicating low contact angle hysteresis. Fujii et al. ${ }^{77}$ fabricated a dual -scale pillared structure of aluminum-niobium (Al-Nb) alloy by combining oblique angle magnetron sputtering deposition and anodic oxidation (see Figures $8 \mathrm{~b}-\mathrm{d}$ ). First, discrete pillars of $\mathrm{Al}-\mathrm{Nb}$ alloy were deposited on a scalloped aluminum substrate through oblique angle magnetron sputtering deposition. Subsequently, the deposited pillars were anodized in hot phosphate, glycerol electrolyte to form a nanoporous oxide layer. Upon modification of this hierarchically textured surface with fluoroalkyl phosphate, the surfaces displayed $\theta^{*}=156^{\circ}$ and $151^{\circ}$ and $\Delta \theta^{*}=2^{\circ}$ and $6^{\circ}$ for rapeseed oil and hexadecane $\left(\gamma_{L V}=27.5\right.$ $\mathrm{mN} \mathrm{m}^{-1}$ ), respectively. Except for a few reports, including the two reports discussed above, rendering surfaces extremely oil-repellant by modifying them with perfluorinated phosphates has not been common.

On the other hand, modifying a surface with perfluorinated silanes has been one of the most common choices to imbue a surface with low surface energy because of the commercial availability of perfluorinated silanes, as well as the ease of the silanization process. Cao et $a l .{ }^{48}$ fabricated hierarchically structured porous silicon films by gold-assisted electroless etching. The surfaces were subsequently silanized using perfluorooctyl trichlorosilane. After silanization, the surfaces displayed a contact angle $\theta^{*}=151^{\circ}$ with hexadecane. Leng et $a .^{3}$ fabricated hierarchically textured cotton textiles that were first coated with positively charged silica microparticles and then coated with negatively charged silica nanoparticles (see Figures $9 a$ and b). First, the silica microparticles were covalently attached to the cotton textile via an in situ Stober reaction (that is, addition of tetraethyl orthosilicate to an aqueous solution of ammonia, methanol and propanol). Upon treating this surface with 3-aminopropyl triethoxysilane and subsequent protonation with hydrochloric acid, the surface charge turned positive. Negatively charged silica nanoparticles were then electrostatically adsorbed onto the surface by dip-coating. The resulting hierarchically textured surface was subsequently silanized with perfluorodecyl trichlorosilane. The resulting surfaces displayed an apparent contact angle as high as $\theta^{*}=152^{\circ}$ and a rolloff angle $\alpha=9^{\circ}$ with hexadecane. Wu et al. ${ }^{78}$ fabricated alumina nanowire forests by electrochemically etching aluminum foils to form a multi-faceted microstructure and subsequently anodizing the activated aluminum to the form the nanowires. Upon silanization with perfluorooctadecyl trichlorosilane, the surfaces displayed $\theta^{*}=155^{\circ}$ and $153^{\circ}$ and $\alpha=5^{\circ}$ and $3^{\circ}$ for rapeseed oil and hexadecane, respectively. Wang et al. ${ }^{79}$ fabricated a hierarchical texture consisting of well-aligned titanium dioxide nanotubes on micropillars of titanium. The micropillars of titanium were fabricated by laser micromachining, and the titanium dioxide nanotubes were fabricated by anodization (see Figure 9c). Upon subsequent silanization with perfluorooctyl trichlorosilane, the surfaces displayed apparent contact angles $\theta^{*}=155^{\circ}, 156^{\circ}$ and $157^{\circ}$ and roll-off angles $\alpha=7^{\circ}$, $6^{\circ}$ and $5^{\circ}$ for hexadecane, colza oil and crude oil, respectively.

In other reports, surface modification was achieved by treating the surface with a fluorinated precursor or a fluorinated monomer or a fluorinated polymer. Ahuja et al. ${ }^{47}$ fabricated silicon nanonail structures with re-entrant texture using reactive ion etching (see Figures $10 \mathrm{a}$ and $\mathrm{b}$ ). When these structures were conformally coated with plasma-assisted chemical vapor deposition using $\mathrm{C}_{4} \mathrm{~F}_{8}$ as the precursor, they displayed $\theta_{a d v}^{*} \approx 155^{\circ}$ with a variety of alcohols (see Figure 10c), including methanol $\left(\gamma_{L V}=22.1 \mathrm{mN} \mathrm{m}^{-1}\right)$, ethanol $\quad\left(\gamma_{L V}=21.8 \mathrm{mN} \mathrm{m}^{-1}\right), \quad$ 1-propanol $\quad\left(\gamma_{L V}=23.7 \mathrm{~m} \mathrm{~N} \mathrm{~m}^{-1}\right)$, 1-butanol $\quad\left(\gamma_{L V}=26.2 \mathrm{mN} \mathrm{m}^{-1}\right), \quad$ 1-octanol $\quad\left(\gamma_{L V}=27.6 \mathrm{mN} \mathrm{m}^{-1}\right)$ and 1-decanol $\left(\gamma_{L V}=28.5 \mathrm{mN} \mathrm{m}^{-1}\right)$. Hsieh et al. ${ }^{80}$ fabricated stacks of silica spheres with a two-tier hierarchical texture by using a two-stage spin-coating technique (see Figures $11 \mathrm{a}-\mathrm{c}$ ). When the surfaces were subsequently spin-coated with a perfluoroalkyl
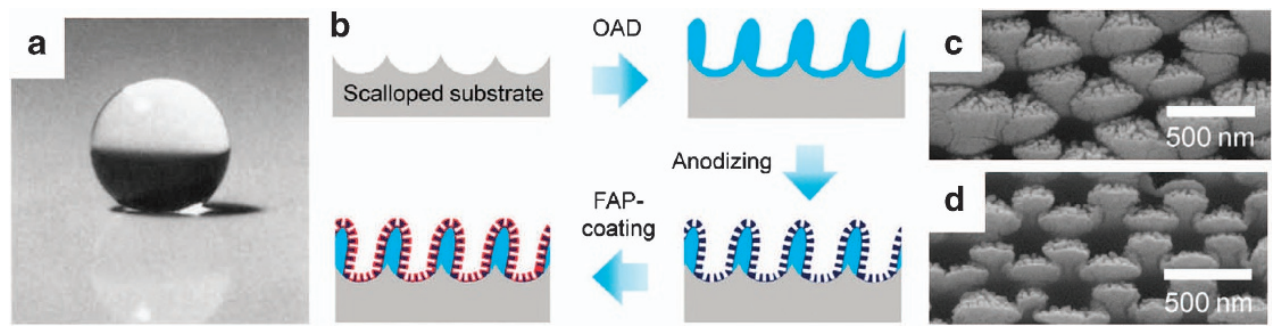

Figure 8 Superomniphobic surfaces modified with perfluorinated phosphates. (a) A droplet of rapeseed oil displaying a very high contact angle of $150^{\circ}$ on a fluorinated, anodically oxidized aluminum surface with a fractal structure. Reprinted with permission from Tsuijii et al. ${ }^{75}$ ( ) 1997 Wiley. (b) A schematic illustration showing the process for fabricating dual-scale pillared surfaces on an aluminum-niobium alloy by combining processes of oblique angle magnetron sputtering deposition (OAD), anodic oxidation and fluoroalkyl phosphate coating. (c, d) S.e.m. images of dual-scale pillared surfaces after OAD with deposition angle of $95^{\circ}$ and $110^{\circ}$, respectively, followed by anodizing. Reprinted with permission from Fujii et al. ${ }^{77}$ (c) 2011 American Chemical Society. 
a
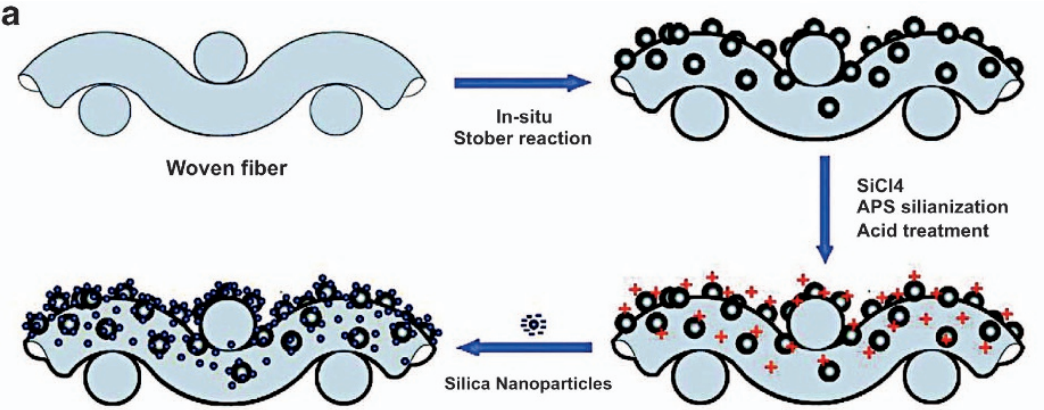

Silica Nanoparticles
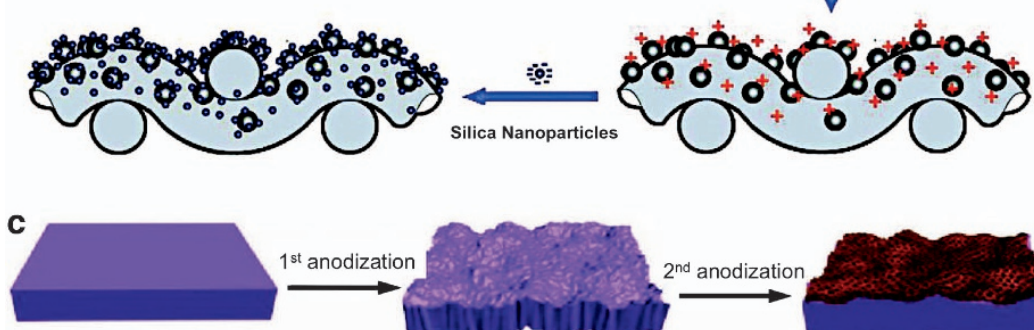

$\mathrm{Ti}$
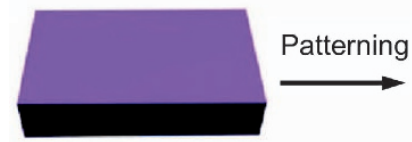

$\mathrm{Ti}$

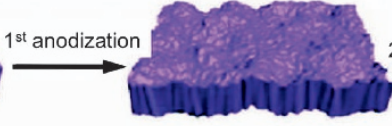

Micro-Ti
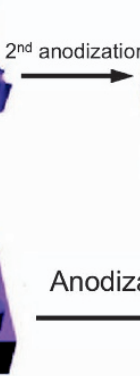

Micro-Ti

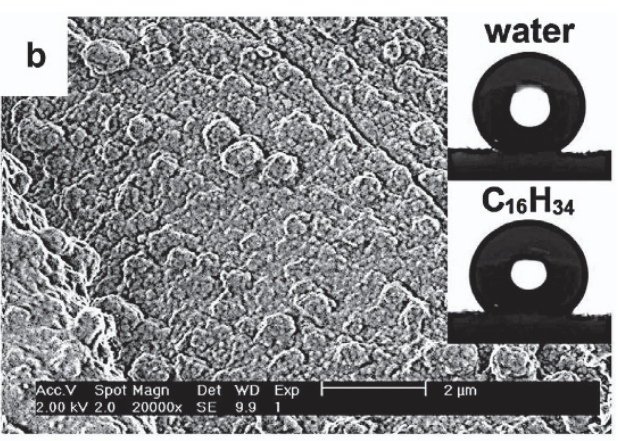

Figure 9 Superomniphobic surfaces modified with perfluorinated silanes. (a) A schematic illustration of the fabrication methodology for synthesizing hierarchically textured superomniphobic cotton textiles. (b) An s.e.m. image illustrating the dual-scale roughness of a woven cotton textile. Insets show droplets of water and hexadecane $\left(\mathrm{C}_{16} \mathrm{H}_{34}\right)$ displaying very high contact angles on the resulting surface. Reprinted with permission from Leng et al. ${ }^{3}$ (c) 2009 American Chemical Society. (c) A schematic illustrating two different methods to fabricate a hierarchical texture consisting of titanium dioxide nanotubes on microstructured titanium surfaces. Reprinted with permission from Wang et al. ${ }^{79} \odot 2010$ American Chemical Society.
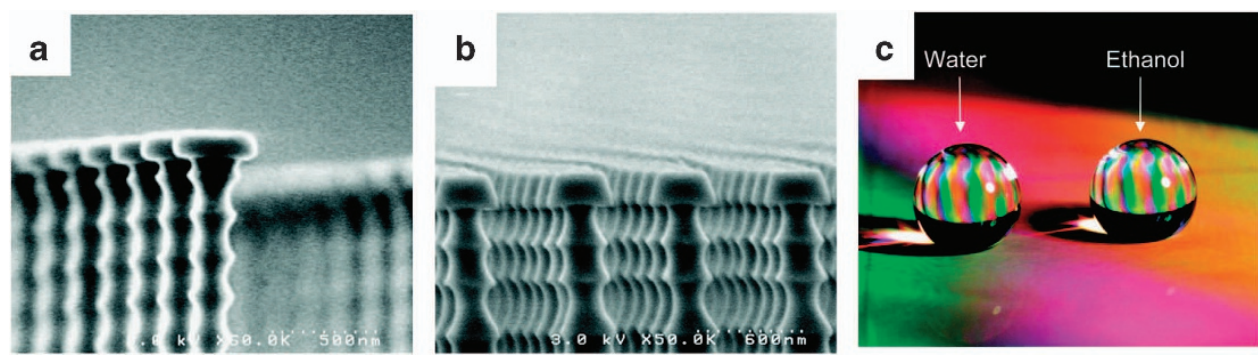

Figure 10 Superoleophobic silicon nanonails. (a, b) S.e.m. images of two different nanonail structures composed of silicon, possessing re-entrant texture. (c) Droplets of water and ethanol displaying very high contact angles on a nanonail substrate. Reprinted with permission from Ahuja et al. ${ }^{47}$ (c) 2008 American Chemical Society.

methacrylic copolymer, they displayed $\theta_{a d v}^{*} \approx 150^{\circ}$ and $\Delta \theta^{*} \approx 3^{\circ}$ for hexadecane. They also measured the contact angle hysteresis for a wide variety of liquids (see Figure 11d) with surface tension values $\gamma_{L V}$ varying between 23.4 and $72.1 \mathrm{mN} \mathrm{m}^{-1}$ and reported that the contact angle hysteresis increased with decreasing $\gamma_{L V}$ on their surfaces. Daramanin et al. ${ }^{81}$ electrochemically deposited spherical nanoporous films of poly(3,4-ethylenedioxypyrrole) on textured micropillar surfaces fabricated using photolithography. These substrates displayed $\theta_{a d v}^{*}=153^{\circ}, \Delta \theta^{*}=35^{\circ}$ and $\alpha=27^{\circ}$ with $6 \mu \mathrm{l}$ hexadecane droplets. However, the same surface displayed much higher contact angles with $6 \mu \mathrm{l}$ sunflower oil droplets $\left(\gamma_{L V}=31 \mathrm{mN} \mathrm{m}^{-1}, \theta_{a d v}^{*}=155^{\circ}, \Delta \theta^{*}=4^{\circ}\right.$ and $\left.\alpha=3^{\circ}\right)$. Yang et al..$^{82}$ fabricated aluminum sheets with a hierarchical structure composed of distorted nanoscale flakes on microscale protrusions (see Figures 11e and f). Although the microscale protrusions and pores were obtained by etching with hydrochloric acid, the nanoscale flakes were obtained by dipping the etched structure in boiling water. Upon modifying the surface with perfluorooctanoic acid, the surface displayed $\theta^{*}=158^{\circ}$, $156^{\circ}, 155^{\circ}$ and $152^{\circ}, \Delta \theta^{*}=5^{\circ}, 8^{\circ}, 18^{\circ}$ and $45^{\circ}$ and $\alpha=5^{\circ}, 7^{\circ}, 15^{\circ}$ and $40^{\circ}$ with $\sim 5 \mu \mathrm{l}$ droplets of rapeseed oil, hexadecane, dodecane $\left(\gamma_{L V}=25.3 \mathrm{mN} \mathrm{m}^{-1}\right)$ and decane $\left(\gamma_{L V}=23.8 \mathrm{mN} \mathrm{m}^{-1}\right)$, respectively, as shown in Figure 11g. In subsequent work, Yang et al. ${ }^{83}$ fabricated hierarchical structures by spray coating a suspension of copper perfluorooctanoate in ethanol (see Figures $11 \mathrm{~h}$ and i). The spraycoated surfaces displayed $\theta^{*}=155^{\circ}$ and $156^{\circ}$ and $\alpha=15^{\circ}$ and $40^{\circ}$ with $\sim 8 \mu \mathrm{l}$ droplets of rapeseed oil and hexadecane, respectively (see Figure 11j). The fabricated surface floats on a bath of hexadecane, as hexadecane cannot penetrate the surface texture (see Figure $11 \mathrm{k}$ ).

There have also been a few reports on developing extremely oilrepellant surfaces using polymer composites. ${ }^{84}$ Steele et al. ${ }^{85}$ spray- 

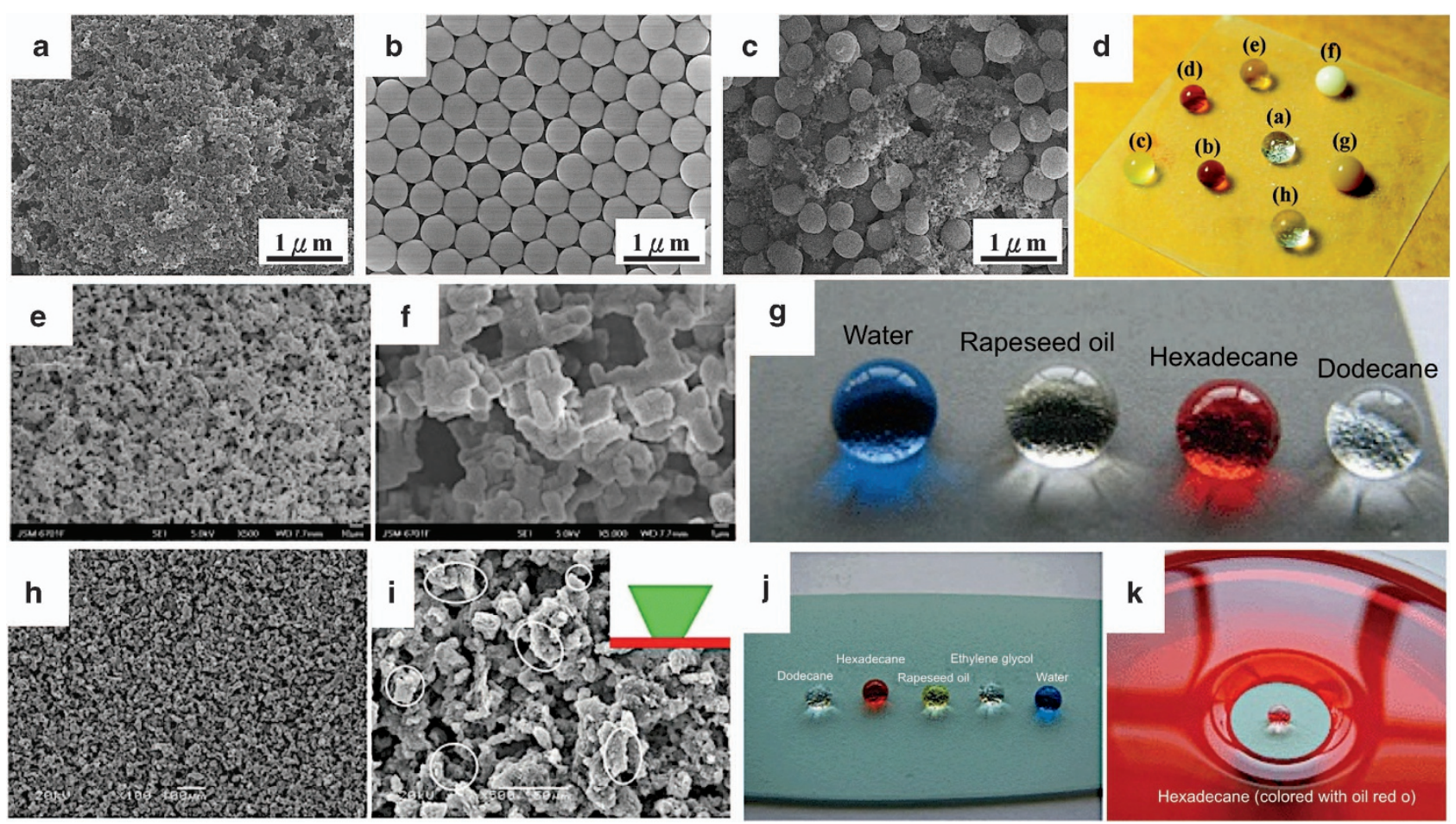

Figure 11 Superomniphobic surfaces with hierarchical structure. (a-c) S.e.m. images of stacks of silica spheres with finer texture, coarser texture and hierarchical texture, respectively. (d) A wide variety of liquid droplets display very high apparent contact angles and low contact angle hysteresis on a hierarchically textured surface coated with a perfluoroalkyl methacrylic copolymer. Reprinted with permission from Hsieh et al.80 (C) 2009 American Chemical Society. (e) An s.e.m. image of microstructures with large numbers of protrusions and pores on the aluminum surface. (f) Magnified s.e.m. image showing Nanoflakes that cover these microstructures. (g) A variety of liquid droplets displaying very high contact angles on the corresponding superomniphobic surface. Reprinted with permission from Yang et al. ${ }^{82}$ (c) 2011 Royal Society of Chemistry. (h-i) S.e.m. images showing a hierarchically textured surface spray-coated with copper perfluorooctanoate at low and high magnifications, respectively. (j) A variety of liquid droplets displaying very high contact angles on the corresponding superomniphobic surface. (k) The spray-coated substrate shown in panel (h) floats on a bath of hexadecane, indicating the high hexadecane repellency of the spray-coated surface. Reprinted with permission from Yang et al.83 (c) 2011 Royal Society of Chemistry.

casted composites of zinc oxide nanoparticles and a perfluoroalkyl methacrylic copolymer on to glass slides using mixtures of water and acetone. The resulting hierarchically structured surfaces displayed $\theta^{*}=154^{\circ}$ and $\Delta \theta^{*}=6^{\circ}$ for hexadecane. In our previous work ${ }^{44-46}$ we fabricated superomniphobic surfaces by electrospinning (see Figures 12a-c) and coating (see Figure 12d) various surfaces with poly(methyl methacrylate)-fluorodecyl POSS blends. Our surfaces displayed $\theta_{a d v}^{*}=156^{\circ}$ and $\Delta \theta^{*}=6^{\circ}$ with hexadecane. In a more recent work, ${ }^{16}$ we fabricated hierarchically structured superomniphobic surfaces, with re-entrant texture at both the coarser and the finer length scales, by electrospinning microbeads of poly(methyl methacrylate)-fluorodecyl POSS blends onto stainless steel wire meshes (see Figures 12e-g). On our surfaces, even extremely low surface tension liquids such as heptane $\left(\gamma_{L V}=20.1 \mathrm{mN} \mathrm{m}^{-1}\right)$ display $\theta_{a d v}^{*}=155^{\circ}$ (see Figure $12 \mathrm{~h}$ ) and $\Delta \theta^{*}=4^{\circ}$. The ultra-low contact angle hysteresis on the hierarchically structured surface is a direct consequence of the reduced solid-liquid contact area. Indeed, an inspection of the vicinity of the triple-phase contact line shows a reduction of the solid-liquid contact area due to the air trapped along both the coarser length scale texture (see Figure 12i) as well as the finer length scale texture (see Figure 12j). The ultra-low contact angle hysteresis of our superomniphobic surfaces allowed $\sim 2 \mu$ d droplets of heptane, as well as liquids possessing a higher surface tension, to easily roll-off $\left(\alpha \leqslant 2^{\circ}\right)$ and bounce on our surfaces (see Figure 12k).
In a more recent work, ${ }^{86}$ we have also developed hierarchically textured, transparent, superomniphobic surfaces. The development of such surfaces is likely to extend the range of applications offered by superomniphobic surfaces onto different transparent substrates, such as windows, phones, tablets and computer screens. These surfaces were developed by spraying poly(dimethylsiloxane) (PDMS)fluorodecyl POSS microparticles onto transparent PDMS pillars fabricated using the standard imprint lithography (see Figure 13a). The spray methodology was chosen as it creates a unique flow field (axisymmetric stagnation point flow $^{87}$ ) that can localize particle deposition on top of the PDMS pillars, helping us fabricate hierarchically textured surfaces (see Figure 13b). Figure 13c shows an iPhone 3GS screen coated with one of our transparent superomniphobic coatings repelling different liquids possessing a range of surface tensions. Figure 13d shows the effect of varying the spraycoating time for the PDMS-fluorodecyl POSS particles on top of the prefabricated PDMS pillars. Essentially, the longer that the pillars are coated, the more repellent they become for low surface tension liquids. However, an increase in spray-coating time also leads to a reduction in transmittance of the fabricated surfaces. These heirarchically textured, transparent, surfaces can repel a range of high and low surface tension liquids and display extremely low contact angle hysteresis (Figure 13e).

In this manner, a wide range of materials from metals to polymers and a wide range of surface coatings from perfluoralkyl silanes to 

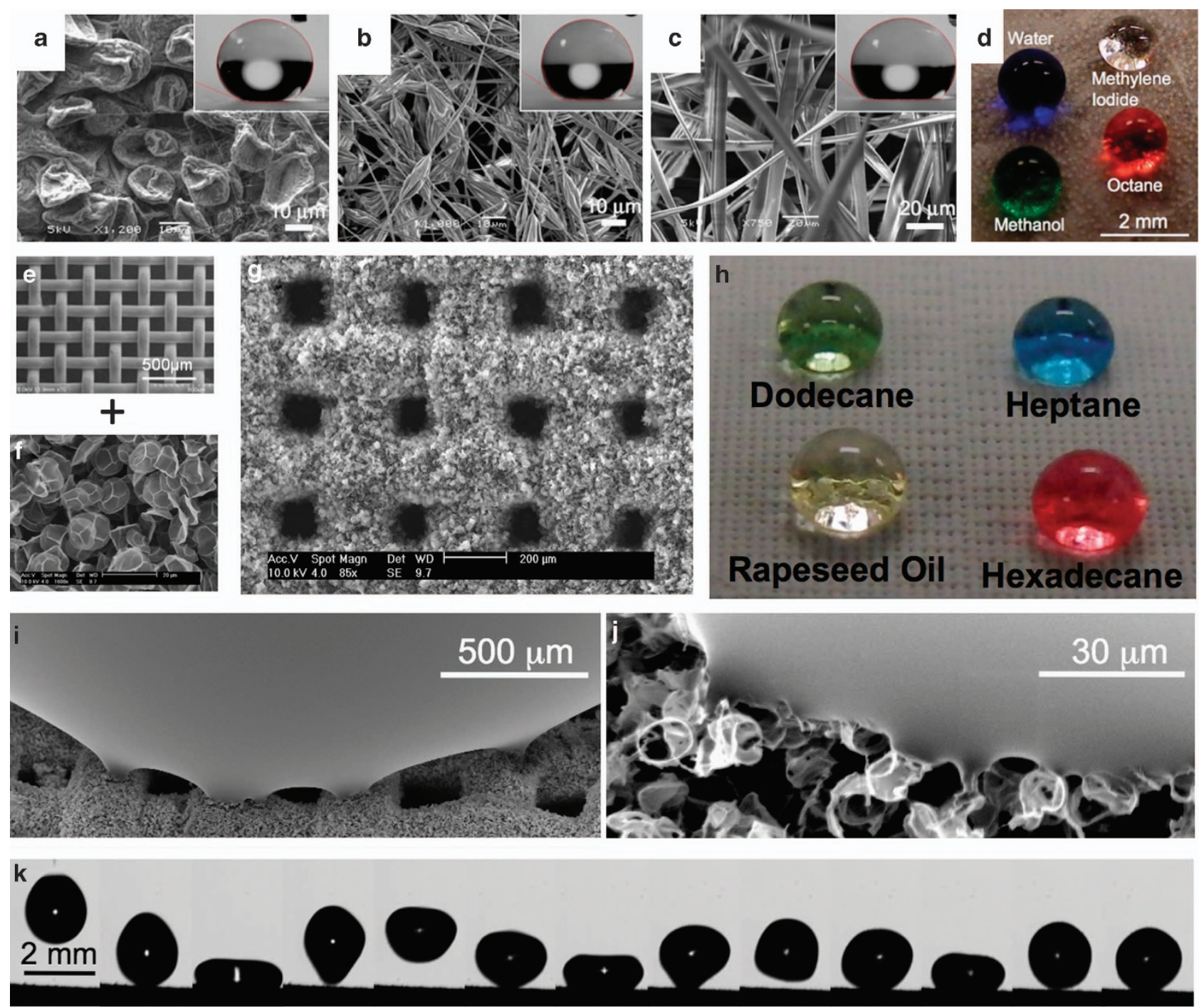

Figure 12 Superomniphobic surfaces fabricated using polymer composites. (a-c) S.e.m. images of various textured electrospun surfaces composed of poly(methyl methacrylate) (PMMA)-fluorodecyl POSS blends showing beads only, beads on strings and fibers only morphologies, respectively. Insets show droplets of hexadecane on each electrospun surface. (d) A lotus leaf coated with electrospun PMMA-fluorodecyl POSS microparticles can repel both high and low surface tension liquids. Reprinted with permission from Tuteja et al. ${ }^{45} \odot 2008$ National Academy of Sciences. (e-g) S.e.m. images of the coarser texture, finer texture, as well as the hierarchically textured surface fabricated by electrospinning microbeads of PMMA-fluorodecyl POSS onto stainless steel wire meshes. (h) A variety of low surface tension liquid droplets display very high contact angles on the corresponding superomniphobic surface. (i, j) S.e.m. images showing the vicinity of the triple-phase contact line along the coarser length scale texture and the finer length scale texture, respectively. (k) A series of snapshots obtained from a high-speed camera showing a droplet of heptane easily bouncing and rolling off of the hierarchically textured superomniphobic surface shown in panel (g). Reprinted with permission from Kota et al. ${ }^{16} \Subset 2012$ Wiley.

fluorinated precursors have been used for the fabrication of superomniphobic surfaces. These results pave the way for further research on developing durable superomniphobic surfaces that are critical for many practical applications.

\section{DURABILITY OF SUPEROMNIPHOBIC SURFACES}

Practical applications of superomniphobic surfaces require good chemical, mechanical and radiation durability. However, developing durable superomniphobic surfaces has thus far been quite a challenge. Under external abrasion, the mechanical durability of a hierarchically structured superomniphobic surface may be compromised easily, because most finer scale textures (typically on the nanoscale) are very delicate and tend to get damaged easily. Further, the finer scale texture, which usually possesses a low surface energy, may easily get delaminated, because it inherently exhibits low adhesion to the underlying surface. This problem is exaggerated further when the finer scale texture is not chemically (or covalently) bonded to the underlying coarser texture. These issues are similar to the challenges faced by hierarchically structured superhydrophobic surfaces. The industrial perspective on the challenges associated with durability of superhydrophobic surfaces is perhaps best provided by Extrand, as noted in his previous work ${ }^{88}$ : 'during one of our technology update forums, we showed water bouncing off a super-hydrophobic surface... The initial response was a combination of amazement and excitement. Enthusiasm quickly waned when one of our executives innocently touched the surface with his finger, destroying its 

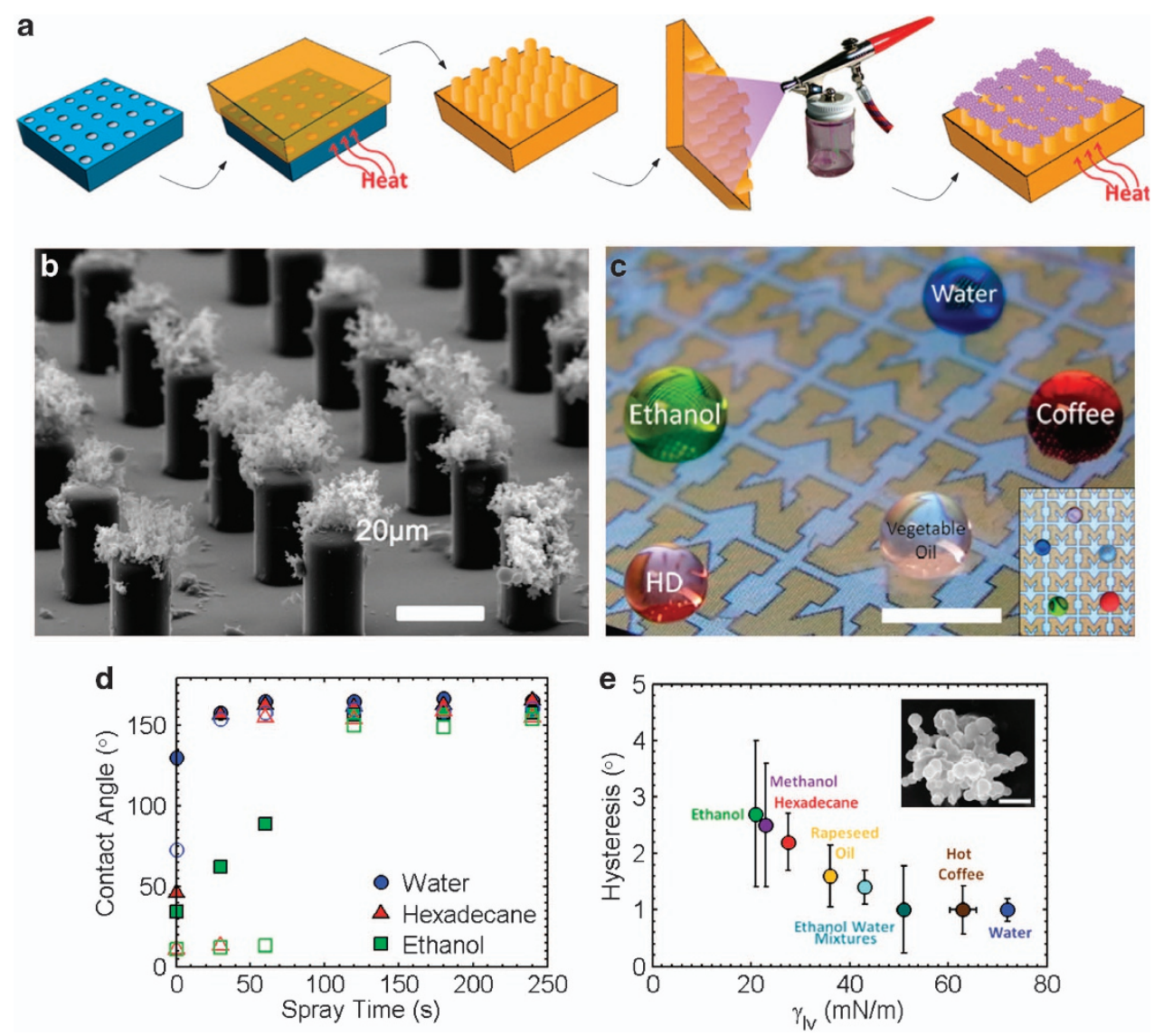

Figure 13 Transparent superomniphobic surfaces. (a) A schematic illustrating the fabrication methodology for transparent superomniphobic surfaces. (b) The hierarchical structure of the superomniphobic surfaces. These structures are produced by spraying poly(dimethylsiloxane) (PDMS) +fluorodecyl POSS blends on top of PDMS pillars fabricated using imprint lithography. (c) Droplets of different high and low surface tension liquids beading up on an Apple iPhone 3GS screen coated with the transparent superomniphobic coating. The inset shows the top view of the same surface. The scale bar is $500 \mu \mathrm{m}$. (d) Contact angle measurements with water, hexadecane and ethanol for pillars with $D^{*}=100$ as a function of spraying time. Filled symbols are advancing angles, and the open symbols are receding contact angles. (e) Contact angle hysteresis as a function of liquid surface tension for the surfaces shown in panel (b) (spray coated for 120s). The inset shows the re-entrant PDMS-fluorodecyl POSS structure; scale bar is $5 \mu \mathrm{m}$. Reprinted with permission from Golovin et al. ${ }^{86}$ ๑) 2013 Wiley.

superhydrophobic nature.' The problem faced by superomniphobic surfaces is perhaps even more pronounced because of the additional requirement of possessing re-entrant texture. One way of potentially improving the mechanical durability is by using monolithic hierarchical structures of mechanically robust materials instead of top-down approaches for depositing the finer scale texture. However, such superomniphobic surfaces are yet to be developed. Similarly, chemical and radiation durability necessitates careful choice of materials that are resistant to harsh chemical environments (such as concentrated acid, bases and solvents) and radiation environments (UV, IR and ozone). Although there is significant scope for developing superomniphobic surfaces with high mechanical, chemical and radiation durability, there are very few reports that address this important issue. In this section, we provide a review of some of the reports on durable, hierarchically structured, superomniphobic surfaces.

Zhang and Seeger ${ }^{89}$ fabricated glass slides coated with nanofilaments of trichloromethylsilane (see Figure 14a) via hydrolysis and condensation. Upon exposing the nanofilaments to oxygen plasma, surface hydroxyl groups are formed. Subsequent silanization with perfluorodecyl trichlorosilane resulted in surfaces that were transparent and superomniphobic for a wide variety of liquids, including mineral oil $\left(\gamma_{L V}=32 \mathrm{mN} \mathrm{m}^{-1}, \theta^{*}=172^{\circ}, \alpha=1.2^{\circ}\right)$, toluene $\left(\gamma_{L V}=28.4 \mathrm{mN} \mathrm{m}^{-1}, \quad \theta^{*}=168^{\circ}, \quad \alpha=2.5^{\circ}\right), \quad p$-xylene $\quad\left(\gamma_{L V}=28.3\right.$ $\left.\mathrm{mN} \mathrm{m}^{-1}, \quad \theta^{*}=171^{\circ}, \alpha=3.0^{\circ}\right)$, hexadecane $\left.\theta^{*}=174^{\circ}, \alpha=2.0^{\circ}\right)$, dodecane $\left(\theta^{*}=167^{\circ}, \alpha=2.3^{\circ}\right)$, cyclohexane $\left(\gamma_{L V}=25 \mathrm{mN} \mathrm{m}^{-1}\right.$, $\left.\theta^{*}=157^{\circ}, \alpha=5.7^{\circ}\right)$ and decane $\left(\theta^{*}=163^{\circ}, \alpha=5.3^{\circ}\right)$. These surfaces were reported to be stable against sodium hydroxide and sulfuric acid, organic solvents, outdoor conditions, ozone, deep UV (see Figure 14b) and temperatures up to $200{ }^{\circ} \mathrm{C}$ for $24 \mathrm{~h}$. Although the chemical and radiation durability of the fabricated surfaces was good, they reported that the mechanical durability needs considerable improvement.

Wang et al. ${ }^{90}$ fabricated superomniphobic surfaces by dip-coating polyester fabrics in a solution of fluorodecyl POSS + fluoroalkyl silane in ethanol (see Figure 14c). The dip-coated fabrics displayed very high apparent contact angles with a wide variety of liquids, including toluene $\left(\theta^{*}=159^{\circ}\right)$ and hexadecane $\left(\theta^{*}=156^{\circ}, \alpha=6^{\circ}\right)$. The surfaces were reported to be stable against UV for $24 \mathrm{~h}$ and against concentrated sulfuric acid (see Figure 14d). Impressively, the fabrics were reported to withstand 6000 cycles of abrasion at $9 \mathrm{kPa}$ (see Figure 14e) and 200 cycles of standard machine laundry (see 

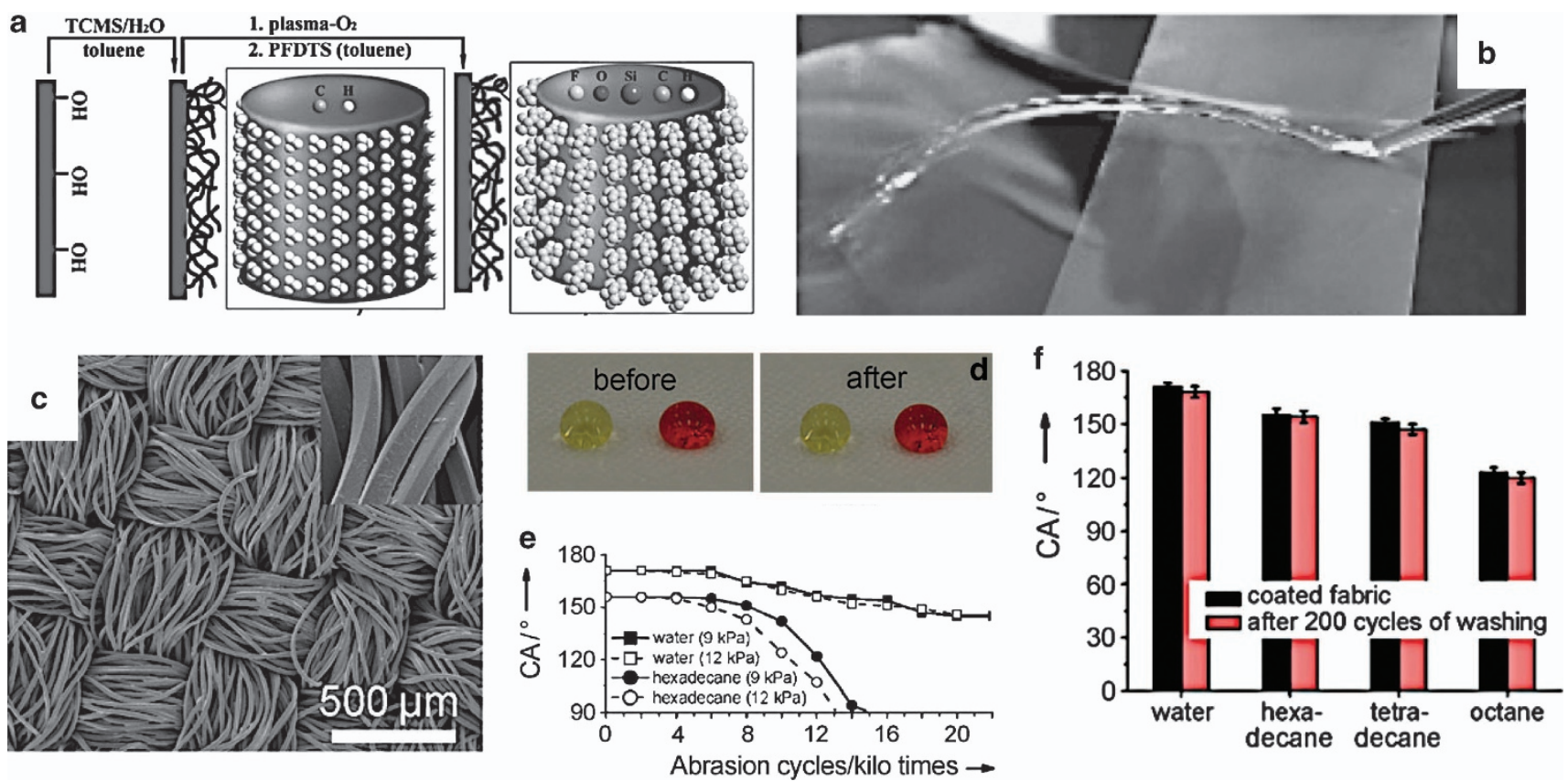

Figure 14 Durable, hierarchically structured, superomniphobic surfaces. (a) A schematic illustrating the fabrication of superomniphobic surfaces with fluorinated silicone nanofilaments, produced by the condensation of silanes. (b) A jet of toluene bouncing off from the corresponding superomniphobic surface, indicating its chemical durability. Reprinted with permission from Zhang and Seeger. ${ }^{89}$ (c) 2011 Wiley. (c) An s.e.m. image of superomniphobic polyester fabrics developed by dip-coating a commercially available polyester fabrics in a solution of fluorodecyl POSS and fluoroalkyl silane in ethanol. (d) Images of droplets of water (yellow) and hexadecane (red) on a superomniphobic fabric surface before and after $24 \mathrm{~h}$ immersion in concentrated sulfuric acid. (e) Contact angles (CAs) for water and hexadecane droplets on a superomniphobic fabric surface as a function of the number of abrasion cycles. (f) CAs for various liquids on a superomniphobic fabric surface before and after the fabric is subjected to 200 cycles of machine wash. Reprinted with permission from Wang et al. ${ }^{90}$ @ 2011 Wiley.
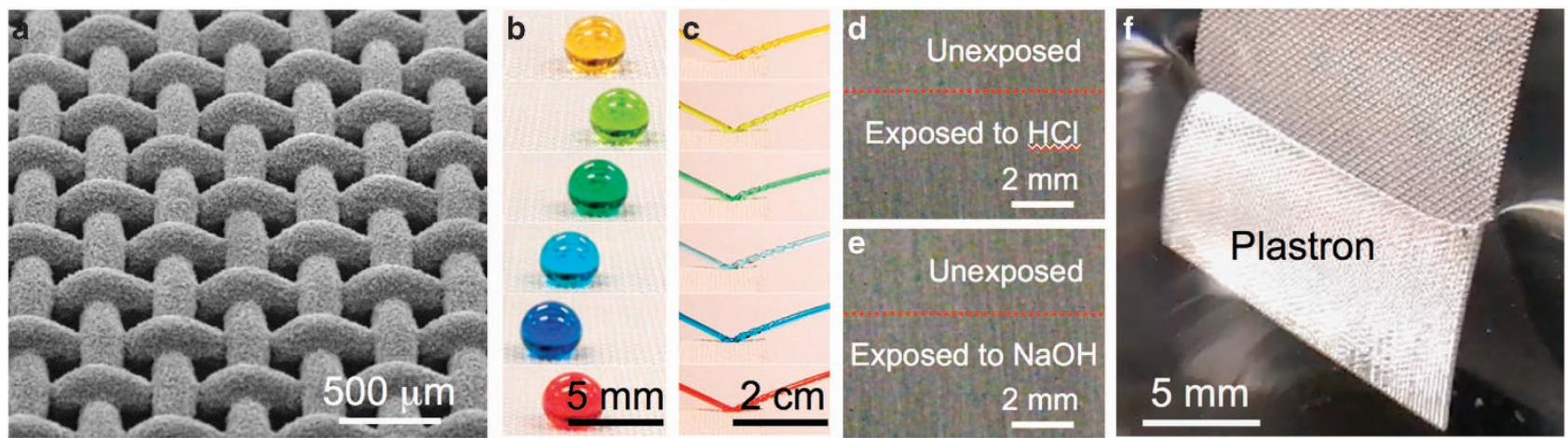

Figure 15 Superommiphobic surfaces as chemical shields. (a) An s.e.m. image of hierarchically textured superomniphobic surface, which consists of stainless steel wire mesh coated with electrospun, cross-linked, poly(dimethylsiloxane) (PDMS)-fluorodecyl POSS microparticles. (b, c) A wide variety of Newtonian liquids display very high contact angles and easily bounce and roll off the superomniphobic surfaces. (d-f) The electrospun coatings remain intact even upon exposure to concentrated acids, bases and PDMS, respectively. The stable plastron layer in (f) indicates that the surface does not reconfigure even when exposed to an enthalpically favorable solvent (in this case, liquid PDMS). Reprinted with permission from Pan et al. ${ }^{5} \odot 2012$ American Chemical Society.

Figure 14f) without any change in the contact angles of water or hexadecane. The good mechanical durability may be due to a covalently bonded fluoroalkyl silane network that is embedded with fluorodecyl POSS molecules. However, they reported that the surfaces showed severe damage when exposed to potassium hydroxide.

In our recent work, we fabricated hierarchically structured superomniphobic surfaces, which possess re-entrant texture at both the finer and coarser length scales, by electrospinning $50 \mathrm{wt} \%$ fluorodecyl
POSS + 50 wt $\%$ cross-linked PDMS blend on top of stainless steel wire meshes (see Figure 15a). Virtually all Newtonian liquids, including concentrated acids, bases and solvents, both organic and inorganic, displayed very high apparent contact angles $\left(\theta^{*}>150^{\circ}\right.$, see Figure 15b) and could easily roll-off $\left(\alpha \leqslant 2^{\circ}\right)$ and bounce (see Figure $15 \mathrm{c}$ ) on the hierarchically structured superomniphobic surfaces. The electrospun coatings remained unaltered (that is, without any additional macroscopic or microscopic rough features due to 
corrosion or dissolution) even upon extended exposure to a wide range of concentrated acids (see Figure 15d), concentrated bases (see Figure 15e), organic solvents or even PDMS itself (see Figure 15f). A stable plastron ${ }^{7,91}$ (that is, air pockets) layer formed when the hierarchically structured superomniphobic surface is submerged under uncrosslinked oligomeric PDMS (see Figure 15f). This indicates that the surface does not reconfigure even when exposed to an enthalpically favorable solvent. Another unique and remarkable feature of these surfaces is that they displayed superomniphobicity with a wide range of non-Newtonian liquids, including polymer solutions of different polymer molecular weights, polymer concentrations and solvents. Due to such effective repellency and chemical durability, these surfaces can act as chemical shields against a wide range of non-Newtonian liquids, in addition to Newtonian liquids.

Deng et al. ${ }^{92}$ fabricated a candle soot morphology coated with a silica shell using chemical vapor deposition of tetraethoxysilane, catalyzed by ammonia. Upon calcination and subsequent silanization with perfluorooctyl trichlorosilane, the surfaces were transparent and superomniphobic for a wide variety of liquids, including peanut oil $\left(\gamma_{L V}=34.5 \mathrm{mN} \mathrm{m}^{-1}, \theta^{*}=158^{\circ}, \alpha=4^{\circ}\right)$, olive oil $\left(\gamma_{L V}=32 \mathrm{mN} \mathrm{m}^{-1}, \theta^{*}=157^{\circ}, \alpha=4^{\circ}\right)$, hexadecane $\left(\theta^{*}=156^{\circ}\right.$, $\left.\alpha=5^{\circ}\right)$ and tetradecane $\left(\gamma_{L V}=26.5 \mathrm{mN} \mathrm{m}^{-1}, \theta^{*}=154^{\circ}, \alpha=5^{\circ}\right)$. The surfaces were reported to be fairly stable under continuous drop impact, sand abrasion and annealing up to $400{ }^{\circ} \mathrm{C}$, but they showed damage under peel tests.

One way of improving the mechanical durability is by developing self-healing superomniphobic surfaces. Although such surfaces may not be able to prevent damage, they can restore the superomniphobicity by an inherent healing mechanism. Recently, Wang et al. ${ }^{93}$ fabricated superomniphobic surfaces utilizing hierarchically structured porous aluminum surfaces that were treated with perfluorooctanoic acid. These surfaces were inspired by the self-healing properties of a lotus leaf, which recovers its superhydrophobicity after any physical damage through the release of wax. Wang et al. pre-filled the pores in the fluorinated aluminum structure with perfluorooctanoic acid. Upon mildly damaging the surface with $\mathrm{O}_{2}$ plasma, the surface gradually, but automatically, healed itself in $48 \mathrm{~h}$ at room temperature by the reaction of perfluorooctyl acid loaded in pores with the plasma-treated surface. However, such a treatment is limited only to mild damage in surface chemistry and cannot address mechanical damage. Thus, fabricating durable superomniphobic surfaces remains an active and exciting area of research.

\section{APPLICATIONS OF SUPEROMNIPHOBIC SURFACES}

The durability of superomniphobic surfaces must be improved before they can be used in commercial applications, including self-cleaning, non-fouling, stain-free clothing and spill-resistant protective wear and drag reduction. Apart from these applications, a few new niche applications of superomniphobic surfaces have started to emerge in the past few years. Some of these applications are discussed next.

Jin et al. ${ }^{7}$ developed ultra lightweight superomniphobic aerogels (see Figure 16a) that can float on both high and low surface tension liquids. The superomniphobic aerogels were fabricated by treating nanocellulose-based aerogel membranes with perfluorinated trichlorosilane. Most significantly, the superomniphobic aerogels
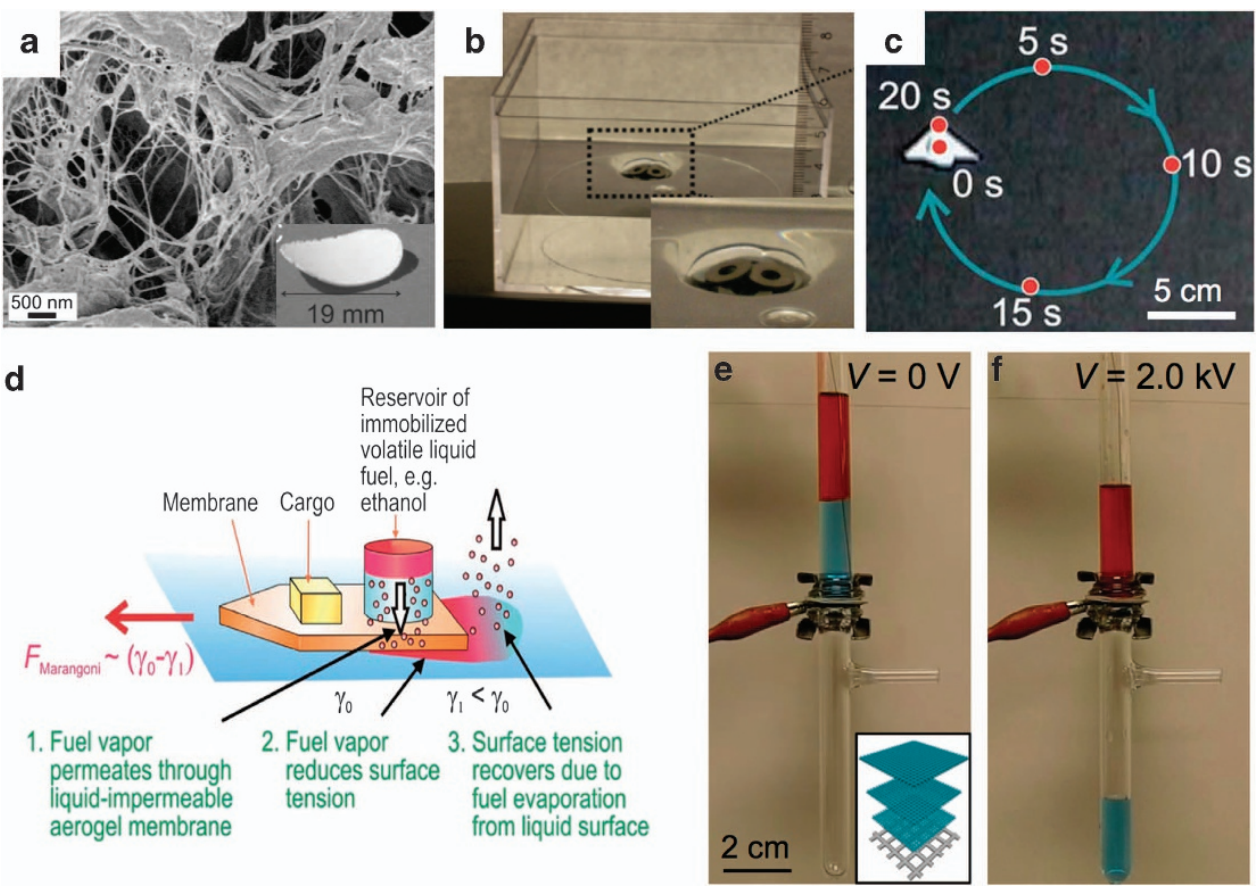

Figure 16 Applications of superomniphobic surfaces. (a) An s.e.m. image of nanocellulose aerogel with highly porous structure. Inset shows a superomniphobic nanocellulose aerogel membrane. (b) Superomniphobic aerogel membrane floats on water (and on various oils) and can carry a weight nearly three orders of magnitude larger than the weight of the aerogel itself. Reprinted with permission from Jin et al. ${ }^{7}$ (c) 2011 American Chemical Society. (c) Superomniphobic aerogel membrane traveling in circular trajectories at steady velocity. (d) A cartoon illustrating self-propulsion of superomniphobic aerogel membrane driven by fuel vapor. Reprinted with permission from Jin et al. ${ }^{94}$ () 2012 Royal Society of Chemistry. (e) A superomniphobic membrane can support a liquid column before the application of an electric field. The inset shows a schematic of the membrane module. (f) Upon application of an electric field, water (blue) permeates through, while hexadecane (red) is retained above the membrane when a voltage $V=2.0 \mathrm{kV}$ is applied. This allows for the facile, on-demand separation of a range of different oil-water mixtures. Reprinted with permission from Kwon et al. ${ }^{8}$ @ 2012 Wiley. 
could carry weight nearly three orders of magnitude larger than the weight of the aerogel itself (see Figure 16b). Such extraordinary load-carrying capacities make these superomniphobic aerogels viable candidates for (a) microrobots that are used in marine reconnaissance operations, and (b) microrobots for environmental sensing in aqueous and chemical environments. In their subsequent work, Jin et al. ${ }^{94}$ imparted their superomniphobic aerogels with the ability to self-propel using vapor-driven marangoni convection (see Figures $16 \mathrm{c}$ and d).

In our recent work, ${ }^{8}$ we developed superomniphobic membranes that can separate polar and non-polar liquid mixtures into almost pure constituents on-demand, that is, when an electric field is applied. The superomniphobic membranes were fabricated by dip-coating interwoven nylon membranes with polymer-fluoroPOSS blends. As a consequence of electrowetting, ${ }^{95-97}$ a polar liquid droplet in the Cassie-Baxter state on a porous membrane can transition to the Wenzel state when an electric field is applied across the porous membrane. ${ }^{98,99}$ Typically, a non-polar liquid does not undergo such a transition. Consequently, upon applying an electric field, the polar liquid permeates through the membrane, while the non-polar liquid is retained above the membrane. Utilizing this preferential wettability transition of polar liquids over non-polar liquids, we demonstrated the on-demand separation of free oil and water, oil-in-water emulsions and water-in-oil emulsions, with $\geqslant 99.9 \%$ separation efficiency (see Figures 16e and f). Such separation opens up new avenues for remote operation of oil-water separation units, microfluidic valves and lab-on-a-chip devices.

\section{CONCLUSIONS AND FUTURE OUTLOOK}

The development of superomniphobic surfaces is an area of significant academic and industrial interest, due to the wide range of applications that can be impacted by the development of such surfaces. In this review, we have discussed the design and synthesis of a range of different superomniphobic surfaces using a wide variety of materials, fabrication methodologies and chemical functionalization techniques. We have also discussed two dimensionless design parameters $D^{*}$ and $A^{*}$, which can greatly aid the rational design of superomniphobic surfaces. The spacing ratio, $D^{*}$, provides a dimensionless measure of surface porosity, while the robustness factor, $A^{*}$, is a measure of a surface's resistance to liquid breakthrough. The development of surfaces with a finer texture, or surfaces with a hierarchical texture, can yield surfaces that simultaneously possess high values for both $D^{*}$ and $A^{*}$. Finally, we have discussed the need for developing superomniphobic surfaces that possess significant chemical, radiation and mechanical durability. Developing such durable superomniphobic surfaces has thus far been a challenge. However, as the interest in this area continues to rise, with an ever-increasing number of scientists and engineers contributing to the development of a range of novel superomniphobic surfaces, we predict an exciting future in the synthesis and commercialization of superomniphobic surfaces.

\section{CONFLICT OF INTEREST}

The authors declare no conflict of interest.

\section{ACKNOWLEDGEMENTS}

We thank Dr Charles Y Lee and the Air Force Office of Scientific Research (AFOSR) for financial support under grant FA9550-11-1-0017. We also thank Dr Ki-Han Kim and the Office of Naval Research (ONR) for financial support under grant N00014-12-1-0874.
1 Sun, T. L., Feng, L., Gao, X. F. \& Jiang, L. Bioinspired surfaces with special wettability. Accounts Chem. Res. 38, 644-652 (2005).

2 Genzer, J. \& Efimenko, K. Recent developments in superhydrophobic surfaces and their relevance to marine fouling: a review. Biofouling 22, 339-360 (2006).

3 Leng, B. X., Shao, Z. Z., de With, G. \& Ming, W. H. Superoleophobic cotton textiles. Langmuir 25, 2456-2460 (2009).

4 Lee, C. \& Kim, C.-J. Underwater restoration and retention of gases on superhydrophobic surfaces for drag reduction. Phys. Rev. Lett. 106, 1-4 (2011).

5 Pan, S. J., Kota, A. K., Mabry, J. M. \& Tuteja, A. Superomniphobic surfaces for effective chemical shielding. J. Am. Chem. Soc. 135, 578-581 (2013).

6 Zhang, X., Zhao, J., Zhu, Q., Chen, N., Zhang, M. \& Pan, Q. Bioinspired aquatic microrobot capable of walking on water surface like a water strider. ACS Appl. Mater. Inter 3, 2630-2636 (2011).

7 Jin, H., Kettunen, M., Laiho, A., Pynnonen, H., Paltakari, J., Marmur, A., Ikkala, O. \& Ras, R. H. A. Superhydrophobic and superoleophobic nanocellulose aerogel membranes as bioinspired cargo carriers on water and oil. Langmuir 27 1930-1934 (2011)

8 Kwon, G., Kota, A. K., Li, Y. X., Sohani, A., Mabry, J. M. \& Tuteja, A. On-demand separation of oil-water mixtures. Adv. Mater. 24, 3666-3671 (2012).

9 Kota, A. K., Choi, W. \& Tuteja, A. Superomniphobic surfaces: Design and durability. MRS Bull. 38, 383-390 (2013).

10 Young, T. An essay on the cohesion of fluids. Philos. Trans. R. Soc. 95, 65-87 (1805)

11 Genzer, J. \& Efimenko, K. Creating long-lived superhydrophobic polymer surfaces through mechanically assembled monolayers. Science 290, 2130-2133 (2000).

12 Nishino, T., Meguro, M., Nakamae, K., Matsushita, M. \& Ueda, Y. The lowest surface free energy based on -CF3 alignment. Langmuir 15, 4321-4323 (1999).

13 Johnson, R. E. \& Dettre, R. H. in: Contact Angle, Wettability and Adhesion, ACS Advances in Chemistry Series Vol. 43 (American Chemical Society, 1964).

14 Johnson, R. E. \& Dettre, R. H. Contact angle hysteresis III: study of an idealized heterogeneous surface. J. Phys. Chem. 68, 1744-1750 (1964).

15 Nosonovsky, M. \& Bhushan, B. Superhydrophobic surfaces and emerging applications: Non-adhesion, energy, green engineering. Curr. Opin. Colloid Interface Sci. 14 270-280 (2009)

16 Kota, A. K., Li, Y., Mabry, J. M. \& Tuteja, A. Hierarchically structured superoleophobic surfaces with ultralow contact angle hysteresis. Adv. Mater. 24, 5838-5843 (2012).

17 Huang, X., Wen, X., Cheng, J. \& Yang, Z. Sticky superhydrophobic filter paper developed by dip-coating of fluorinated waterborne epoxy emulsion. Appl. Surf. Sci. 258, 8739-8746 (2012).

18 Dufour, R., Harnois, M., Coffinier, Y., Thomy, V., Boukherroub, R. \& Senez, V. Engineering sticky superomniphobic surfaces on transparent and flexible PDMS substrate. Langmuir 26, 17242-17247 (2010).

19 Guo, Z.-G. \& Liu, W.-M. Sticky superhydrophobic surface. Appl. Phys. Lett. 90, 1-3 (2007).

20 Jin, M. H., Feng, X. J., Feng, L., Sun, T. L., Zhai, J., Li, T. J. \& Jiang, L. Superhydrophobic aligned polystyrene nanotube films with high adhesive force. Adv Mater. 17, 1977-1981 (2005).

$21 \mathrm{Xi}$, J. \& Jiang, L. Biomimic superhydrophobic surface with high adhesive forces. Ind Eng. Chem. Res. 47, 6354-6357 (2008).

22 Balu, B., Breedveld, V. \& Hess, D. W. Fabrication of 'roll-off' and 'sticky' superhydrophobic cellulose surfaces via plasma processing. Langmuir 24, 4785-4790 (2008)

23 Lai, Y., Lin, C., Huang, J., Zhuang, H., Sun, L. \& Nguyen, T. Markedly controllable adhesion of superhydrophobic spongelike nanostructure TiO2 films. Langmuir 24 3867-3873 (2008)

24 Kim, P., Wong, T.-S., Alvarenga, J., Kreder, M. J., Adorno-Martinez, W. E. \& Aizenberg, J. Liquid-infused nanostructured surfaces with extreme anti-ice and antifrost performance. ACS Nano 6, 6569-6577 (2012).

25 Lafuma, A. \& Quere, D. Slippery pre-suffused surfaces. EPL 96, 56001 (2011)

26 Wong, T.-S., Kang, S. H., Tang, S. K. Y., Smythe, E. J., Hatton, B. D., Grinthal, A. \& Aizenberg, J. Bioinspired self-repairing slippery surfaces with pressure-stable omniphobicity. Nature 477, 443-447 (2011).

27 Quere, D. Non-sticking drops. Rep. Prog. Phys. 68, 2495-2532 (2005).

28 Smith, J. D., Dhiman, R., Anand, S., Reza-Garduno, E., Cohen, R. E., McKinley, G. H. \& Varanasi, K. K. Droplet mobility on lubricant-impregnated surfaces. Soft Matter $\mathbf{9}$ 1772-1780 (2013)

29 Rykaczewski, K., Anand, S., Subramanyam, S. B. \& Varanasi, K. K. Mechanism of frost formation on lubricant-impregnated surfaces. Langmuir 29, 5230-5238 (2013).

30 Richard, D. \& Quere, D. Bouncing water drops. Europhys. Lett. 50, 769-775 (2000).

31 Barthlott, W. \& Neinhuis, C. Purity of the sacred lotus, or escape from contamination in biological surfaces. Planta 202, 1-8 (1997).

32 Neinhuis, C. \& Barthlott, W. Characterization and distribution of water-repellent, selfcleaning plant surfaces. Ann. Bot. 79, 667-677 (1997).

33 Koch, K., Bohn, H. F. \& Barthlott, W. Hierarchically sculptured plant surfaces and superhydrophobicity. Langmuir 25, 14116-14120 (2009).

$34 \mathrm{Hu}$, D. L., Chan, B. \& Bush, J. W. M. The hydrodynamics of water strider locomotion. Nature 424, 663 (2003)

35 Hu, D. L. \& Bush, J. W. M. Meniscus-climbing insects. Nature 437, 733-736 (2005).

$36 \mathrm{Gao}, \mathrm{X}$. \& Jiang, L. Biophysics: water-repellent legs of water striders. Nature 432, 36 (2004).

37 Autumn, K., Liang, Y. A., Hsieh, S. T., Zesch, W., Chan, W. P., Kenny, T. W., Fearing, R. \& Full, R. J. Adhesive force of a single gecko foot-hair. Nature 405, 681-685 (2000) 
38 Parker, A. R. \& Lawrence, C. R. Water capture by a desert beetle. Nature 414, 33-34 (2001).

39 Wagner, T., Neinhuis, C. \& Barthlott, W. Wettability and contaminability of insect wings as a function of their surface sculptures. Acta Zool. 77, 213-225 (1996).

40 Bhushan, B. \& Jung, Y. C. Natural and biomimetic artificial surfaces for superhydrophobicity, self-cleaning, low adhesion, and drag reduction. Prog. Mater. Sci. 56, 1-108 (2011).

41 Chen, W., Fadeev, A. Y., Hsieh, M. C., Oner, D., Youngblood, J. \& McCarthy, T. J. Ultrahydrophobic and ultralyophobic surfaces: some comments and examples. Langmuir 15, 3395-3399 (1999).

42 Lafuma, A. \& Quéré, D. Superhydrophobic states. Nat. Mater. 2, 457-460 (2003).

43 Helbig, R., Nickerl, J., Neinhuis, C. \& Werner, C. Smart skin patterns protect springtails. PLOS ONE 6, e25105 (2011).

44 Choi, W., Tuteja, A., Chhatre, S., Mabry, J. M., Cohen, R. E. \& McKinley, G. H. Fabrics with tunable oleophobicity. Adv. Mater. 21, 2190-2195 (2009).

45 Tuteja, A., Choi, W., Mabry, J. M., McKinley, G. H. \& Cohen, R. E. Robust omniphobic surfaces. Proc. Natl Acad. Sci. USA 105, 18200-18205 (2008).

46 Tuteja, A., Choi, W., Ma, M. L., Mabry, J. M., Mazzella, S. A., Rutledge, G. C., McKinley, G. H. \& Cohen, R. E. Designing superoleophobic surfaces. Science 318, 1618-1622 (2007)

47 Ahuja, A., Taylor, J. A., Lifton, V., Sidorenko, A. A., Salamon, T. R., Lobaton, E. J., Kolodner, P. \& Krupenkin, T. N. Nanonails: a simple geometrical approach to electrically tunable superlyophobic surfaces. Langmuir 24, 9-14 (2008).

48 Cao, L., Price, T. P., Weiss, M. \& Gao, D. Super water- and oil-repellent surfaces on intrinsically hydrophilic and oleophilic porous silicon films. Langmuir 24, 1640-1643 (2008).

49 Marmur, A. From Hygrophilic to superhygrophobic: theoretical conditions for making high-contact-angle surfaces from low-contact-angle materials. Langmuir $\mathbf{2 4}$ 7573-7579 (2008)

50 Coulson, S. R., Woodward, I., Badyal, J. P. S., Brewer, S. A. \& Willis, C. Super-repellent composite fluoropolymer surfaces. J. Phys. Chem. B 104, 8836-8840 (2000).

51 Coulson, S. R., Woodward, I. S., Badyal, J. P. S., Brewer, S. A. \& Willis, C. Ultralow surface energy plasma polymer films. Chem. Mater. 12, 2031-2038 (2000)

52 Marmur, A. Wetting on hydrophobic rough surfaces: to be heterogeneous or not to be? Langmuir 19, 8343-8348 (2003).

53 Nosonovsky, M. Multiscale roughness and stability of superhydrophobic biomimetic interfaces. Langmuir 23, 3157-3161 (2007).

54 Herminghaus, S. Roughness-induced non-wetting. Europhys. Lett. 52, 165-170 (2000).

55 Liu, K. S., Tian, Y. \& Jiang, L. Bio-inspired superoleophobic and smart materials: design, fabrication, and application. Prog. Mater. Sci. 58, 503-564 (2013)

56 Kota, A. K. \& Tuteja, A. in Advances in Fluorine-Containing Polymers Vol. 1106, ACS Symposium Series Ch. 11, 171-185 (American Chemical Society, Washington, DC, USA, 2012).

57 Kota, A. K., Mabry, J. M. \& Tuteja, A. Superoleophobic surfaces: design criteria and recent studies. Surf. Innov. 1, 71-83 (2013).

58 Kota, A. K., Kwon, G., Choi, W., Mabry, J. M. \& Tuteja, A. Hygro-responsive membranes for effective oil-water separation. Nat. Commun. 3, 1025 (2012).

59 Yang, J., Zhang, Z., Xu, X., Zhu, X., Men, X. \& Zhou, X. Superhydrophilic-superoleophobic coatings. J. Mater. Chem. 22, 2834-2837 (2012).

60 Cassie, A. B. D. \& Baxter, S. Wettability of porous surfaces. Trans. Faraday Soc. 40, 0546-0550 (1944)

61 Hare, E. F., Shafrin, E. G. \& Zisman, W. A. Properties of films of adsorbed fluorinated acids. J. Phys. Chem. 58, 236-239 (1954).

62 Mabry, J. M., Vij, A., lacono, S. T. \& Viers, B. D. Fluorinated polyhedral oligomeric silsesquioxanes (F-POSS). Angew. Chem. Int. Ed. 47, 4137-4140 (2008).

63 Shuttleworth, R. \& Bailey, G. L. J. The spreading of a liquid over a rough solid. Discuss. Faraday Soc. 3, 16-22 (1948).

64 Patankar, N. A. On the modeling of hydrophobic contact angles on rough surfaces. Langmuir 19, 1249-1253 (2003).

65 Wenzel, R. N. Resistance of solid surfaces to wetting by water. Ind. Eng. Chem. 28, 988-994 (1936).

66 Milne, A. J. B. \& Amirfazli, A. The Cassie equation: how it is meant to be used. Adv. Colloid Interface Sci. 170, 48-55 (2012).

67 Choi, W., Tuteja, A., Mabry, J. M., Cohen, R. E. \& McKinley, G. H. A modified CassieBaxter relationship to explain contact angle hysteresis and anisotropy on non-wetting textured surfaces. J. Colloid Interf. Sci. 339, 208-216 (2009).

68 Callies, M. \& Quéré, D. On water repellency. Soft Matter 1, 55-61 (2005).

69 Bhushan, B. \& Jung, Y. C. in Nanotribology and Nanomechancis // Ch. 20, 533-699 (Springer-Verlag, Berlin, Germany, 2011).

70 Gao, L. C. \& McCarthy, T. J. The 'lotus effect' explained: two reasons why two length scales of topography are important. Langmuir 22, 2966-2967 (2006).

71 Su, Y., Ji, B., Huang, Y. \& Hwang, K. C. Nature's design of hierarchical superhydrophobic surfaces of a water strider for low adhesion and low-energy dissipation. Langmuir 26, 18926-18937 (2010).

72 Su, Y., Ji, B., Zhang, K., Gao, H., Huang, Y. \& Hwang, K. Nano to micro structural hierarchy is crucial for stable superhydrophobic and water-repellent surfaces. Langmuir 26, 4984-4989 (2010).
73 Bittoun, E. \& Marmur, A. The role of multiscale roughness in the lotus effect: is it essential for super-hydrophobicity? Langmuir 13933-13942 (2012).

74 Chhatre, S. S., Choi, W., Tuteja, A., Park, K. C., Mabry, J. M., McKinley, G. H. \& Cohen, R. E. Scale dependence of omniphobic mesh surfaces. Langmuir 26, 4027-4035 (2010).

75 Tsujii, K., Yamamoto, T., Onda, T. \& Shibuichi, S. Super oil-repellent surfaces. Angew. Chem. Int. Ed. 36, 1011-1012 (1997).

76 Shibuichi, S., Yamamoto, T., Onda, T. \& Tsujii, K. Super water- and oil-repellent surfaces resulting from fractal structure. J. Colloid Interface Sci. 208, 287-294 (1998).

77 Fujii, T., Aoki, Y. \& Habazaki, H. Fabrication of super-oil-repellent dual pillar surfaces with optimized pillar intervals. Langmuir 27, 11752-11756 (2011).

78 Wu, W., Wang, X., Wang, D., Chen, M., Zhou, F., Liu, W. \& Xue, Q. Alumina nanowire forests via unconventional anodization and super-repellency plus low adhesion to diverse liquids. Chem. Commun. 1043-1045 (2009).

79 Wang, D., Wang, X., Liu, X. \& Zhou, F. Engineering a titanium surface with controllable oleophobicity and switchable oil adhesion. J. Phys. Chem. C 114, 9938-9944 (2010).

80 Hsieh, C. T., Wu, F. L. \& Chen, W. Y. Contact angle hysteresis and work of adhesion of oil droplets on nanosphere stacking layers. J. Phys. Chem. C 113, 13683-13688 (2009).

81 Darmanin, T., Guittard, F., Amigoni, S., de Givenchy, E. T., Noblin, X., Kofman, R. \& Celestini, F. Superoleophobic behavior of fluorinated conductive polymer films combining electropolymerization and lithography. Soft Matter 7, 1053-1057 (2011).

82 Yang, J., Zhang, Z., Xu, X., Men, X., Zhu, X. \& Zhou, X. Superoleophobic textured aluminum surfaces. New J. Chem. 35, 2422-2426 (2011).

83 Yang, J., Zhang, Z. Z., Men, X. H., Xu, X. H. \& Zhu, X. T. A simple approach to fabricate superoleophobic coatings. New J. Chem. 35, 576-580 (2011).

84 Xue, Z., Liu, M. \& Jiang, L. Recent developments in polymeric superoleophobic surfaces. J. Polym. Sci. Pol. Phys. 50, 1209-1224 (2012).

85 Steele, A., Bayer, I. \& Loth, E. Inherently superoleophobic nanocomposite coatings by spray atomization. Nano Lett. 9, 501-505 (2009).

86 Golovin, K., Lee, D. H., Mabry, J. M. \& Tuteja, A. Transparent, flexible, superomniphobic surfaces with ultra-low contact angle hysteresis. Angew. Chem. Int. Ed. 52, 13007-13011 (2013)

87 White, F. M. Viscous Fluid Flow (McGraw-Hill Professional Publishing, New York, NY, USA, 1991)

88 Youngblood, J. P., Sottos, N. R. \& Extrand, C. Bioinspired materials for self-cleaning and self-healing. MRS Bull. 33, 732-741 (2008)

89 Zhang, J. P. \& Seeger, S. Superoleophobic coatings with ultralow sliding angles based on silicone nanofilaments. Angew. Chem. Int. Ed. 50, 6652-6656 (2011).

90 Wang, H., Xue, Y., Ding, J., Feng, L., Wang, X. \& Lin, T. Durable, self-healing superhydrophobic and superoleophobic surfaces from fluorinated-decyl polyhedral oligomeric silsesquioxane and hydrolyzed fluorinated alkyl silane. Angew. Chem. Int. Ed. 50, 11433-11436 (2011).

91 Shirtcliffe, N. J., McHale, G., Newton, M. I., Perry, C. C. \& Pyatt, F. B. Plastron properties of a superhydrophobic surface. Appl. Phys. Lett. 89, 104106 (2006).

92 Deng, X., Mammen, L., Butt, H. J. \& Vollmer, D. Candle soot as a template for a transparent robust superamphiphobic coating. Science 335, 67-70 (2012).

93 Wang, X., Liu, X., Zhou, F. \& Liu, W. Self-healing superamphiphobicity. Chem. Commun. 47, 2324-2326 (2011).

94 Jin, H., Marmur, A., Ikkala, O. \& Ras, R. H. A. Vapour-driven Marangoni propulsion: continuous, prolonged and tunable motion. Chem. Sci. 3, 2526-2529 (2012).

95 Mugele, F. \& Baret, J. C. Electrowetting: from basics to applications. J. Phys. Condens. Mater. 17, R705-R774 (2005).

96 Shamai, R., Andelman, D., Berge, B. \& Hayes, R. Water, electricity, and between... On electrowetting and its applications. Soft Matter 4, 38-45 (2008).

97 Gras, S. L., Mahmud, T., Rosengarten, G., Mitchell, A. \& Kalantar-Zadeh, K. Intelligent control of surface hydrophobicity. Chem. Phys. Chem. 8, 2036-2050 (2007).

98 Manukyan, G., Oh, J. M., van den Ende, D., Lammertink, R. G. H. \& Mugele, F. Electrical switching of wetting states on superhydrophobic surfaces: a route towards reversible cassie-to-wenzel transitions. Phys. Rev. Lett. 106, 014501 (2011).

99 Oh, J. M., Manukyan, G., van den Ende, D. \& Mugele, F. Electric-field-driven instabilities on superhydrophobic surfaces. EPL 93, 56001 (2011).

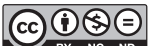

This work is licensed under a Creative Commons Attribution-NonCommercial-NoDerivs 3.0 Unported License. The images or other third party material in this article are included in the article's Creative Commons license, unless indicated otherwise in the credit line; if the material is not included under the Creative Commons license, users will need to obtain permission from the license holder to reproduce the material. To view a copy of this license, visit http://creativecommons.org/licenses/by-nc-nd/3.0/ 


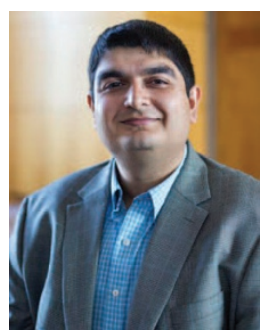

Anish Tuteja received his $\mathrm{PhD}$ in Chemical Engineering from Michigan State University in 2006. From 2006 to 2009, he worked as a Postdoctoral Associate at the Massachusetts Institute of Technology. In 2009, he joined the Department of Materials Science and Engineering at the University of Michigan, where he currently serves as an Assistant Professor. His current research interests include superomniphobic surfaces, icephobic surfaces, liquid-liquid separations, patterned surfaces and microfluidics.

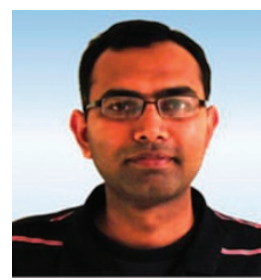

Arun Kota received his PhD in Mechanical Engineering from the University of Maryland in 2008. From 2009 to 2013, he worked as a Postdoctoral Fellow with Professor Anish Tuteja in the Department of Materials Science and Engineering at the University of Michigan. In 2013, he joined the Department of Mechanical Engineering at the Colorado State University, where he currently serves as an Assistant Professor. His current research interests include superomniphobic surfaces and fluid dynamics of bouncing droplets.

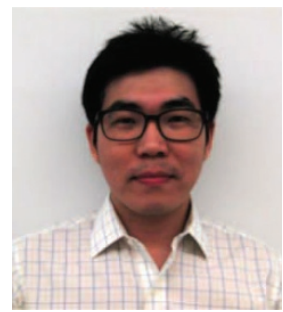

Gibum Kwon is currently a PhD student in the Department of Materials Science and Engineering at the University of Michigan. He received his BS degree in the same department from the Seoul National University, Republic of Korea in 2008. In 2009, he joined Professor Tuteja's group at the University of Michigan. His current research interests include superomniphobic surfaces and stimuliresponsive membranes to separate liquid-liquid mixtures. 